University of South Florida

DIGITAL COMMONS

Digital Commons @ University of

@ UNIVERSITY OF SOUTH FLORIDA

South Florida

June 2017

\title{
Treatment of Food Selectivity: An Evaluation of Video Modeling of Contingencies
}

\author{
Erin O'Connor \\ University of South Florida, erino@mail.usf.edu
}

Follow this and additional works at: https://digitalcommons.usf.edu/etd

Part of the Social and Behavioral Sciences Commons

\section{Scholar Commons Citation}

O'Connor, Erin, "Treatment of Food Selectivity: An Evaluation of Video Modeling of Contingencies" (2017). USF Tampa Graduate Theses and Dissertations.

https://digitalcommons.usf.edu/etd/6918

This Thesis is brought to you for free and open access by the USF Graduate Theses and Dissertations at Digital Commons @ University of South Florida. It has been accepted for inclusion in USF Tampa Graduate Theses and Dissertations by an authorized administrator of Digital Commons @ University of South Florida. For more information, please contact digitalcommons@usf.edu. 
Treatment of Food Selectivity: An Evaluation of Video Modeling of Contingencies

by

\begin{abstract}
Erin O’Connor
A thesis submitted in partial fulfillment

of the requirements for the degree of Master of Arts

Applied Behavior Analysis

Department of Child and Family Studies

College of Behavioral and Community Science

University of South Florida
\end{abstract}

Major Professor: Catia Cividini-Motta, Ph.D., BCBA-D

Kimberly Crosland, Ph.D., BCBA-D

Raymond G. Miltenberger, PhD., BCBA-D

Date of Approval:

June 30, 2016

Keywords: differential reinforcement, escape extinction, food refusal, video modeling 


\section{Table of Contents}

List of Figures iii

Abstract iv

Introduction. 1

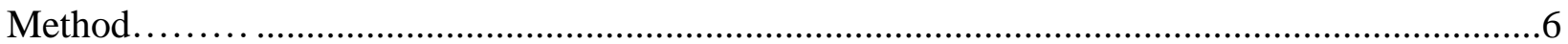

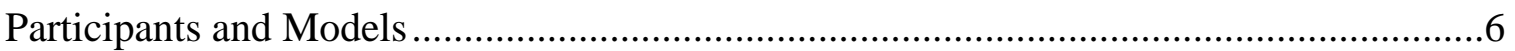

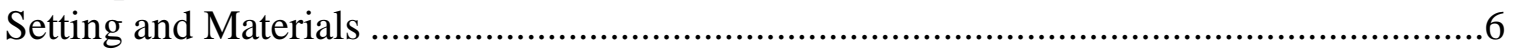

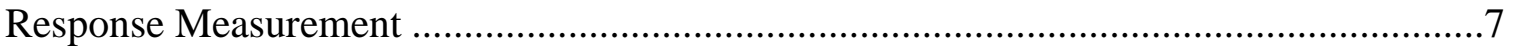

Treatment Integrity and Interobserver Agreement ………...........................................

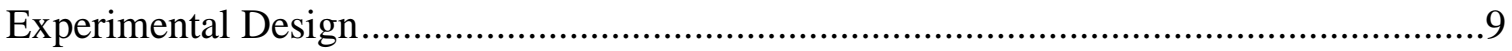

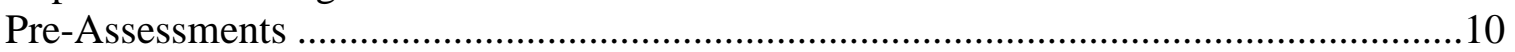

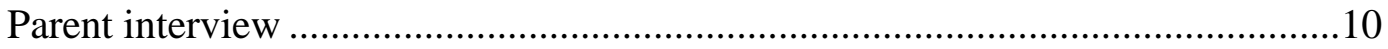

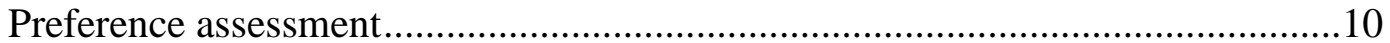

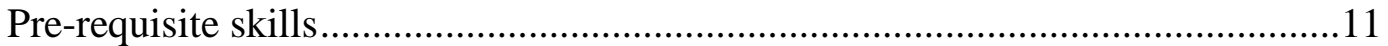

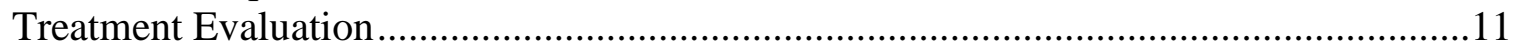

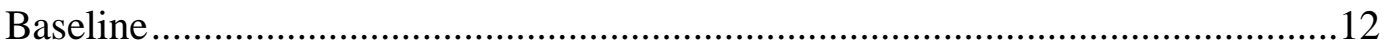

Video modeling (VM) .................................................................................13

Video modeling of differential reinforcement (VM of DR) ..................................13

Video modeling of differential reinforcement plus differential reinforcement (VM of DR + DR) ........................................................................

Video modeling of differential reinforcement/non-removal of spoon plus differential reinforcement (VM of DR/NRS + DR) .................................14

Generalization probes ………………..........................................................15

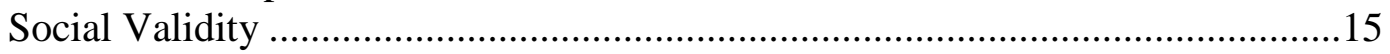

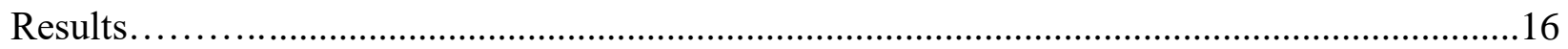

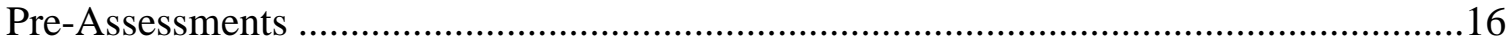

Preference assessment ..............................................................................16

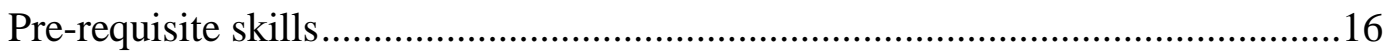

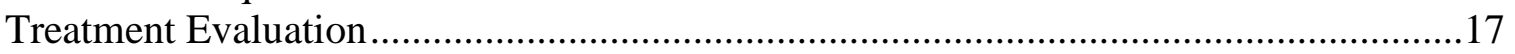

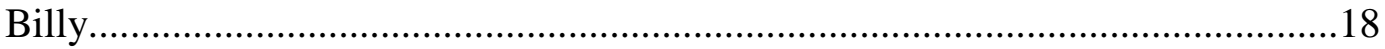

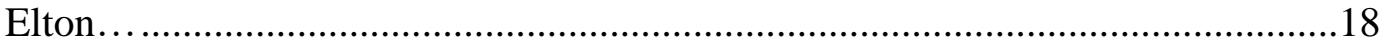

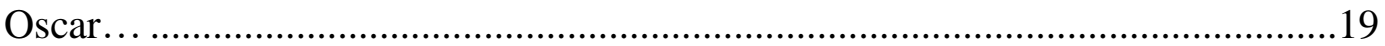

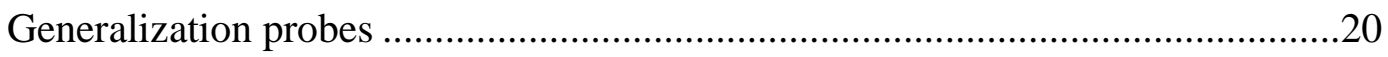

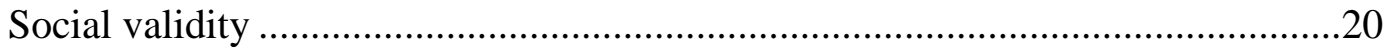

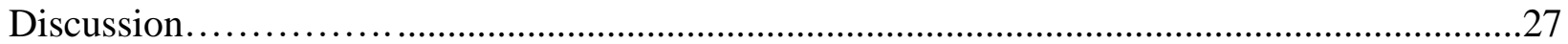




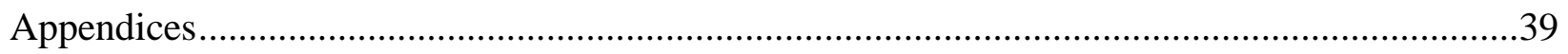

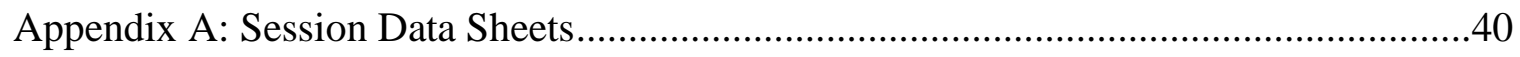

Appendix B: Treatment Integrity Checklists ........................................................41

Appendix C: Reinforcement Assessment for Individuals with Severe Disabilities

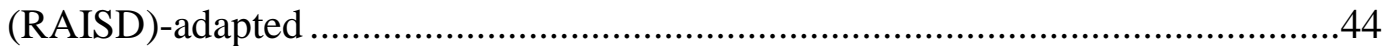

Appendix D: Video Modeling Screening Procedures (MacDonald et al., 2015) ..............46

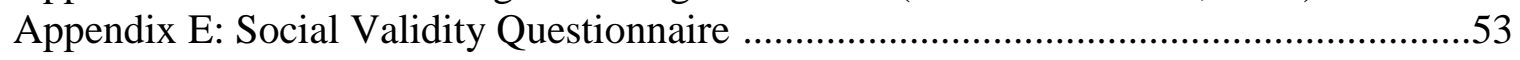

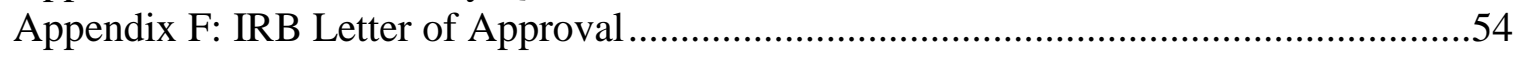




\section{List of Figures}

Figure 1: Percentage of bites accepted across participants and phases ....................................21

Figure 2: Percentage of bites consumed across participants and phases. .................................22

Figure 3: Percentage of trials with IMB across participants and phases. .................................23

Figure 4: Generalization probes, percentage of bites accepted for Food A and B across

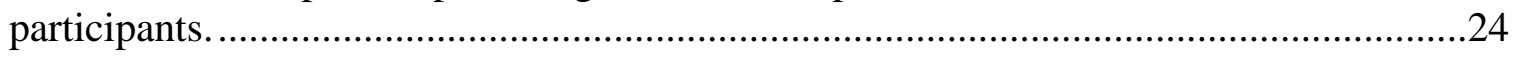

Figure 5: Generalization probes, percentage of bites consumed for Food A and B across

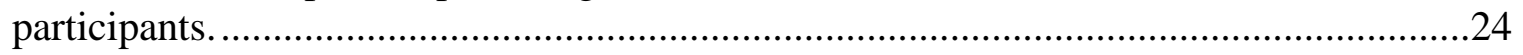

Figure 6: Generalization probes, percentage of trials with IMB for Food A and B across

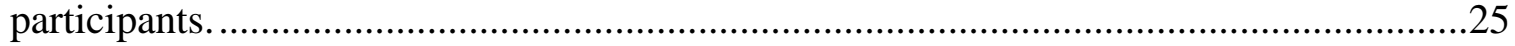

Figure 7: Generalization probes, percentage of bites accepted for Food C. .............................25

Figure 8: Generalization probes, percentage of bites consumed for Food C............................26

Figure 9: Generalization probes, percentage of trials with IM for Food C...............................26 


\begin{abstract}
The purpose of this study was to evaluate the effectiveness of video modeling of contingencies alone and/or combined with direct exposure to the contingencies in the treatment of food selectivity. Treatment procedures included sequentially introducing videos in which models consumed nonpreferred food, were exposed to differential reinforcement, or exposed to escape extinction and differential reinforcement. In addition, participants were exposed to differential reinforcement. Results indicated video modeling of differential reinforcement plus differential reinforcement may be effective at increasing consumption of some nonpreferred foods, but the results were not replicated across all foods. For one participant, consumption of one food increased with video modeling alone.
\end{abstract}




\section{Introduction}

Children with autism and developmental disabilities are more likely than their typically developing peers to have feeding problems (Schreck, Williams, \& Smith, 2004; Sharp et al., 2013). In fact, some estimate the prevalence of such problems is as high $80-90 \%$ in children with disabilities (Bandini et al., 2010; DeMeyer, 1979; Perske, Clifton, McLean, \& Stein, 1977; Sharp et al., 2013). Food selectivity and refusal, two common types of feeding problems, can lead to many negative side effects including, malnutrition, impaired physical development or growth, invasive medical procedures (e.g., gastronomy tubes), hospitalization, and increased familial stress (Kerwin, 1999; Sharp, Jaquess, Morton, \& Herzinger, 2010; Singer, Song, Hill, \& Jaffe, 1990). Given that food selectivity and refusal pose risks to children's health and familial wellbeing, effective interventions that increase food consumption and reduce inappropriate mealtime behavior (IMB) are warranted.

Research has shown that when oral-motor deficits have been ruled out, behavioral interventions are the most effective and empirically-supported treatments for feeding problems (e.g., Kerwin, 1999; Sharp, Jaquess, et al., 2010). Two categories of behavioral interventions include antecedent interventions and consequent interventions. Antecedent-based interventions to increase food consumption include simultaneous presentation (e.g., Buckley \& Newchok, 2005; Kern \& Marder, 1996; Piazza et al., 2002; Riordan, Iwata, \& Wohl, 1980), stimulus fading (e.g., Luiselli, Ricciardi, \& Gilligan, 2005; Patel, Piazza, Kelly, Ochsner, \& Santana, 2001; Shore, Babbitt, Williams, Coe, \& Snyder, 1998; Tiger \& Hanley, 2006), utensil manipulations (e.g., Girolami, Boscoe, \& Roscoe, 2007; Sharp, Harker, \& Jaquess, 2010; Wilkins et al., 2014), 
high-probability instructional sequences (e.g., Meier, Fryling, \& Wallace, 2012; Patel et al., 2007; Penrod, Gardella, \& Fernand, 2012), and noncontingent reinforcement (e.g., Allison et al., 2012; Reed et al., 2004). The efficacy of many antecedent-based interventions is likely related to specific food aversions and the severity of the feeding problem (Seubert, Fryling, Wallace, Jimenez, \& Meier, 2014; Sharp \& Jaquess, 2009). Research on the use of antecedent-based interventions often involves a treatment package, thus the exact mechanism of behavior change is often unknown. Furthermore, these procedures may result in the development of taste aversions for preferred food and may require an extended amount of time to be effective (Bachmeyer, 2009).

Consequence-based interventions to increase food consumption and/or decrease IMB include differential reinforcement (DR), and escape extinction (EE) in the form of non-removal of spoon (NRS) or physical guidance. Researchers have used preferred foods, praise, or access to preferred toys or activities as positive reinforcement (e.g., Levin \& Carr, 2001; Riordan, Iwata, Finney, Wohl, \& Stanley, 1984; Wilder, Normand, \& Atwell, 2005), and brief escape from mealtime as negative reinforcement (e.g., LaRue et al., 2011; Piazza, Patel, Gulotta, Sevin, \& Layer, 2003) to increase acceptance and consumption. Moreover, researchers have shown reinforcement-based procedures to be more effective when appropriate establishing operations are present (Levin \& Carr, 2001). However, reinforcement alone may not result in increased acceptance and consumption in all individuals (e.g., Ahearn, 2002; LaRue et al., 2011; Piazza, Patel, et al., 2003), but may be used to enhance the efficacy of other treatments such as EE (e.g., Cooper et al., 1995; Hoch, Babbit, Coe, Krell, \& Hackbert, 1994).

Researchers frequently use EE to increase acceptance and consumption and/or decrease IMB in children presenting with food selectivity or refusal (e.g., Borrero, Schlereth, Rubio, \& 
Taylor, 2013; LaRue et al., 2011; Piazza et al., 2002; Reed et al., 2004). Researchers have usually implemented EE by presenting food at the participant's mouth until the food is accepted (NRS) or by physically guiding the participant's mouth to open so food can be delivered (physical guidance). Both methods have been found to be effective (e.g., Ahearn, Kerwin, Eicher, Shantz, \& Swearingin, 1996; LaRue et al., 2011; Piazza et al., 2002). However, the effectiveness of EE procedures may depend on other concurrently-implemented interventions. For instance, EE may be more effective when combined with attention extinction, representation, or utensil manipulation (e.g., Bachmeyer et al., 2009; Hoch et al., 2001; Wilkins et al., 2014). In addition, EE procedures may result in an increase in problem behavior, particularly aggression and emotional responding (e.g., Bachmeyer, 2009; Lerman, Iwata, \& Wallace, 1999), possibly hindering implementation of EE (Bachmeyer, 2009; Hoch et al., 1994). Thus, procedures that may attenuate these side effects, such as using rich schedules of reinforcement or combining extinction and reinforcement procedures (e.g., Lerman et al., 1999), must be considered.

Another procedure that has been found effective with individuals with disabilities is video modeling $(\mathrm{VM})$. This procedure is an evidence-based practice in which the participant watches a video of the target behavior being performed correctly and then attempts to perform the target behavior himself (Bellini \& Akullian, 2007; Bidwell \& Rehfelt, 2004; Nikopolous \& Keenan, 2003). Research has shown VM to be an efficient and effective method for teaching a variety of behaviors to individuals with autism and developmental disabilities (e.g., Acar \& Diken, 2012; Mason, Ganz, Parker, Burke, \& Camargo, 2012; Plavnick, 2012). Compared to invivo modeling, VM can lead to faster acquisition (Charlop-Christy, Le, \& Freeman, 2000), and provides a cost-effective and consistent means to teach skills (Boudreau \& D'Entremont, 2010). Furthermore, research has shown VM is generally approved of by caregivers (Cardon, Guimond, 
\& Smith-Treadwell, 2015), is most effective with children (Mason et al., 2012) and may be more effective when combined with positive reinforcement procedures (Mason et al., 2012).

Currently, no research found has evaluated the use of VM in the treatment of food selectivity; however, studies assessing treatment packages that included in-vivo modeling have had positive results (i.e., Fu et al., 2015; Greer, Dorow, Williams, McCorkle, \& Anes, 1991; Seiverling, Harclerode, \& Williams, 2014; Sira \& Fryling, 2012). In these studies, participants experienced modeling (i.e., observed another person consume a target food or engage in IMB, and then observed the delivery of consequences following the person's food consumption or IMB) combined with direct exposure to contingencies such as reinforcement and/or EE (i.e., consequences were delivered to the participant for food consumption and/or IMB). These studies have found that, in general, food consumption increased when modeling was combined with direct exposure to reinforcement of food consumption (e.g., Greer et al., 1991; Sira \& Fryling, 2012) or direct exposure to reinforcement of food consumption and EE (e.g., Seiverling et al., 2014).

Although Seiverling et al. (2014) showed direct exposure to EE may be necessary to increase consumption, Fu et al. (2015) demonstrated that, in some cases, observing another individual experience EE may also be effective for increasing food consumption. Fu et al. evaluated modeling of DR combined with direct exposure to DR, and modeling of DR and EE (consisting of NRS) combined with direct exposure to DR, and demonstrated an increase in consumption to $100 \%$ when modeling of DR and EE combined with direct exposure to DR was implemented. Thus, the intervention was effective without the participants directly contacting the potentially aversive EE procedures. However, it should be noted that modeling was implemented after participants were provided an opportunity to take a bite and did not consume the food. In 
these procedures, the modeling intervention may have served as reinforcement for not consuming the food. Additionally, given each treatment phase included multiple components, it is unclear which components of the intervention are necessary.

Research has found that in-vivo modeling may be effective with or without EE for increasing food consumption and/or decreasing IMB. However, the research is limited in that these studies included few participants and did not assess prerequisite skills which may be necessary for participants to learn effectively through modeling. Furthermore, no identified study has evaluated VM in the treatment of food selectivity. Therefore, the purpose of this study is to evaluate the effectiveness of VM of contingencies alone as an antecedent intervention and VM combined with direct exposure to the contingencies if needed in the treatment of food selectivity. 


\section{Method}

\section{Participants and Models}

Three children diagnosed with an autism spectrum disorder (ASD) of normal height and weight according to parent report participated in the study. None of the participants had physical problems related to eating or a history of medical treatment for health problems associated with food refusal, as per parent report. All participants scored at least $75 \%$ on all VM prerequisite skills assessments. All participants communicated in full sentences, and independently expressed their wants and needs. Billy was a 10-year-old boy who was being homeschooled. Billy's diet consisted mostly of chicken nuggets, French fries, yogurt, grilled cheese, pizza, fruit snacks, yogurt, and chips. Elton was a 12-year-old boy who attended a special education middle school. Elton's diet consisted mostly of hash browns, pancakes, French fries, macaroni and cheese, and candy. Oscar was a 5-year-old boy placed in a preschool classroom. Oscar's diet consisted mostly of chicken nuggets, some fruits, candy, nuts, and peanut butter. Parental consent and child assent was obtained prior to starting the project. Typically-developing peer models of similar age to each participant were used in the videos. The peer model for each participant was kept consistent across treatment videos. The principal investigator (PI) implemented the intervention and collected all data, using session protocols to guide sessions. Sessions were conducted one to three times per week with each participant.

\section{Setting and Materials}

Sessions were conducted in the same designated room of the participants' homes across all sessions: Billy and Oscar sat at their kitchen tables; and Elton sat in his living room at a 
coffee table. Participants sat within arms' reach of the PI. Required materials included plates, appropriate utensils, microwave, timers, foods (target and preferred), preferred toys and activities, video camera, laptop computer, six different colored placemats to act as discriminative stimuli during each phase, stimulus boards and pictures of stimuli for the VM skills assessments, common household objects (e.g., ball, cup, spoon) for the VM skills assessments, and paper and pencil for data collection. Video cameras were used to create treatment videos and record treatment sessions. Laptop computers were used to play treatment videos during sessions. The scenes recorded for the VM conditions included a table, chairs, a placemat, a plate with the target food, preferred food and activities, the PI, and the model. The videos ranged from approximately 10s to 90 s in length.

\section{Response Measurement}

Data were collected using paper and pencil on a trial-by-trial basis (see Appendix A). Acceptance was defined as the participant placing the bite of target food in his mouth, past the plane of his lips within 5s of vocal prompt. Consumption was defined as the participant swallowing the target food within 30s of acceptance as demonstrated by a mouth check. For Elton, no vomiting within 10 s of mouth check was added to the definition of consumption. Occurrence or nonoccurrence of acceptance and consumption were scored by the PI during each trial, and summarized as percentage of bites accepted and consumed per session. Percentage of bites accepted or consumed was calculated by dividing number of bites accepted or consumed by number of bites presented, and then multiplying by 100 . Because the topography was different across participants, $I M B$ was individually defined for each participant. For Billy, IMB was defined as any instance of verbal refusal (e.g., "I don't want it", but excluding "no thank you”), negative comments about the food (e.g., "It's disgusting"), spitting the food out after acceptance, 
or placing head on table for at least 2s. For Elton, IMB was defined as any instance of verbal refusal (e.g., "I don't want to eat it", but excluding "no thank you"), negative comments about the food (e.g., "I don't like it”), spitting the food out after acceptance, or vomiting within 10s of mouth check. For Oscar, IMB was defined as any instance of verbal refusal (e.g., "I don't want to", but excluding "no thank you"), screaming (i.e., words or utterances said loud enough to be heard in the next room), or spitting the food out after acceptance. Occurrence or nonoccurrence of IMB during each trial was scored by the PI and summarized as percentage of trials with IMB per session. Percentage of trials with IMB per session was calculated by dividing the number of trials in which IMB occurred by the total number of trials and multiplying by 100 .

\section{Treatment Integrity and Interobserver Agreement}

Data on treatment integrity and interobserver agreement (IOA) were collected by trained research assistants for at least $33 \%$ of sessions for each phase for all participants. Treatment integrity was measured to evaluate whether the PI implemented the treatment as prescribed in the session description (see Appendix B), including presenting the food and treatment videos at the correct time, and providing the correct consequence corresponding to the session. Treatment integrity scores were calculated by dividing the number of steps completed correctly by the total number of steps and multiplying by 100 . Treatment integrity scores were calculated for $37 \%$ of all sessions: 45.5\% for Billy, 38.5\% for Elton, 33.8\% for Oscar. Treatment integrity scores averaged $99.8 \%$ (range, 91\%-100\%). We calculated IOA for acceptance, consumption, and IMB using a trial-by-trial method in which the number of trials with agreement was divided by total trials and multiplied by 100 to give a percentage of trials with agreement. We calculated IOA for 37\% of all sessions: $45.6 \%$ for Billy, $37.9 \%$ for Elton, and $33.7 \%$ for Oscar. The percentage of 
agreement for all participants averaged $97.1 \%$ for acceptance (range, $80 \%-100 \%$ ), $99.7 \%$ for consumption (range $80 \%-100 \%$ ), and $95.2 \%$ for IMB (range, 60\%-100\%).

\section{Experimental Design}

The study employed a combination of a nonconcurrent multiple baseline across participants design and a multiple probe design across food. At least two foods were targeted for each participant. Food B was randomly assigned to remain in baseline and probes were completed every three sessions, with at least one probe completed prior to introducing a new treatment for the food in the intervention condition, Food A. In addition, probes of consumption of Food A, similar to baseline, were completed every three treatment sessions after consumption increased to $100 \%$. Once consumption of Food A met the mastery criterion (100\% for three sessions), the effective intervention, as determined by visual analysis, was implemented with Food B. If acceptance and consumption of Food B did not meet the mastery criterion in the same phase as Food A, a third food, Food C, was introduced. Food C remained in baseline with probes conducted every three sessions while the remaining treatments were sequentially implemented with Food B. After Food B met mastery or all treatments had been implemented without mastery, the effective intervention for Food A was implemented with Food C. Treatments were sequentially introduced with Food $\mathrm{C}$ until consumption increased to $100 \%$.

\section{Overview}

Prior to beginning the treatment evaluation, a series of assessments was completed to identify nonpreferred edibles, preferred edibles, and preferred tangibles for each participant. Prerequisite skills for VM were also evaluated prior to treatment evaluation. During treatment evaluation, the efficacy of VM alone and combined with direct exposure to the contingencies was assessed using procedures similar to Fu et al. (2015). However, this study differed in that 
recorded videos were used instead of in-vivo modeling, the videos were presented prior to bite presentations (unless conducting baseline or baseline probe session), no statements of contingencies were provided, and the effectiveness of VM compared to VM plus direct exposure to contingencies was assessed separately and then added sequentially as necessary to increase acceptance and consumption. Additionally, bites were presented individually and, during treatment phases in which consequences were provided, reinforcement was provided immediately after consumption of each bite. All participants were allowed a drink during treatment sessions.

\section{Pre-Assessments}

Parent interview. An adapted version of Reinforcer Assessment for Individuals with Severe Disabilities (Fisher, Piazza, Bowman, \& Amari, 1996) was used to inform items to be used during preference assessments. The questionnaire (see Appendix C) included questions related to participants' preferred foods, nonpreferred foods, and preferred items and activities.

Preference assessment. Three paired-choice preference assessments, similar to procedures described by Fisher et al. (1992), were conducted with each participant before baseline to identify nonpreferred foods, preferred foods, and preferred tangibles. Each preference assessment assessed eight items, randomly presented two at a time with positions counterbalanced across trials. Each item was paired with all other items two times, for a total of 56 trials per assessment. The PI provided breaks within and between preference assessments. Participants were given a chance to sample novel items before beginning the preference assessments. Two or three nonpreferred foods (i.e., those never consumed during assessment) were selected based on parent preference and randomly ordered in baselines. Preferred foods were identified as those consumed at least $70 \%$ of trials during the assessments. A third 
preference assessment was conducted to determine preferred tangibles (i.e., those selected around $80 \%$ of trials).

Pre-requisite skills. The PI assessed each participant's performance on delayed imitation of actions with objects (i.e., 3s delay between modeling and opportunity to perform one-step action), delayed picture-to-object match to sample (i.e., 3s delay between sample picture and opportunity to identify identical object from comparison stimuli), delayed computer picture-to-object match to sample (i.e., same procedures as previous but using a computer), and attending to a video (i.e., duration of attending to 3 min highly-preferred video as indicated by orienting eyes and head toward the screen) as these skills have been identified as potential prerequisites for learning through VM (MacDonald et al., 2015). According to MacDonald et al., participants who scored at least $75 \%$ on these assessments tended to perform well on VM tasks, indicating they had the prerequisite skills to effectively learn through VM. Discrete trial format was used in which two sessions with nine trials were conducted for the first three assessments. Nine actions, kept consistent across sessions, were used during the delayed imitation of action with objects assessment. Six items, three different items for each session, were used during both match to sample assessments. The final assessment (i.e., attending to a video) consisted of one session with a 3 min video. Participants were provided a 3 min break between sessions. Participants were required to score at least $75 \%$ on each assessment task to continue participation in the evaluation of VM of contingencies. These procedures were based on those described by MacDonald et al. For a detailed description of the assessments, see Appendix D.

\section{Treatment Evaluation}

During treatment evaluation the efficacy of video modeling, video modeling of differential reinforcement, video modeling of differential reinforcement plus differential 
reinforcement, and video modeling of differential reinforcement/non-removal of the spoon plus differential reinforcement were assessed. These treatments were introduced sequentially. At least three sessions per condition were conducted until mastery criterion was met (i.e., $100 \%$ acceptance and consumption across three consecutive sessions). The number of sessions per phase was adjusted for Elton and Oscar to account for staggered baselines and phases. Introduction of treatment phases was staggered to evaluate whether introduction of treatment for one participant affected the targeted behavior of another participant. After at least three sessions were conducted, the trend and slope of the data were evaluated to determine when to introduce the next treatment. If no progress or a decreasing trend was observed, the next treatment phase was introduced. If food consumption was increasing, but the mastery criterion was not met, additional sessions were completed. Sessions were completed about the same time of the day to minimize fluctuations in motivating operations correlated with meal consumption. Across baseline and treatment phases, sessions consisted of five trials, where one trial consisted of one presentation of a bite of target food. Each trial was presented individually (i.e., each bite of the target food was presented on its own plate). The plate was put on top of the placemat of the designated color for the current phase. In phases where programmed consequences were to be delivered, the PI delivered consequences after each trial. The PI conducted at least three sessions each visit, providing participants about 3-10 min breaks between sessions. Sessions ranged between approximately 1 and $10 \mathrm{~min}$. Small bite sizes (approximately $1.5 \mathrm{~cm}$ by $1.5 \mathrm{~cm}$ ) were presented.

Baseline. In this phase, the PI presented a small bite of the target food (approximately 1.5 $\mathrm{cm}$ by $1.5 \mathrm{~cm}$ ) on a plate on a blue placemat in front of the participant with a vocal prompt (e.g., "It's time to eat," or "Take a bite."). The PI waited 5s for independent approach (i.e., reaching 
for, touching or picking up the target food) or acceptance and conducted a mouth check after $30 \mathrm{~s}$ if participant accepted the target food. If the participant approached the food, the PI waited an additional $5 \mathrm{~s}$ for acceptance. The PI removed the plate without comment after $5 \mathrm{~s}$ without approach or acceptance, or when the bite was been consumed. During baseline no programmed consequences were delivered for approach, acceptance, consumption or IMB. The same procedure was implemented for the remaining four trials after approximately $5 \mathrm{~s}$ delay between trials.

Video modeling (VM). A yellow placemat was used in VM sessions. In this phase, procedures for the target food were the same as baseline except the PI played a video clip to the participant, then presented the bite of target food. The video clip in this phase showed the PI presenting the target food with a vocal prompt, and the model consuming and appearing to enjoy the food (e.g., smiling and vocal comment such as, "Yummy!") with no programmed consequences delivered. The procedure continued for the remaining trials, with $5 \mathrm{~s}$ delay between trials. If the participant was not looking at the video, the PI used a vocal and gestural prompt (e.g., "watch the video" while pointing at the computer screen). The same procedures as baseline were used for approach, acceptance and consumption. Again, no programmed consequences were delivered.

Video modeling of differential reinforcement (VM of DR). A red placemat was used during VM of DR sessions. The procedures in this phase were the same as the previous phase, with the following exceptions: the video clips in this phase included the PI prompting the model to choose from one of the participant's preferred edibles and tangibles (in the first clip only) and the PI providing DR to the model contingent on consumption. That is, the PI provided a praise statement (e.g., "great job taking a bite of [target food]") and access to a preferred edible or 
tangible after each bite the model consumed. The first video clip displayed all preferred items as determined by the results of the participant's preference assessment. The model's selection remained within the video scene for the remainder of the video clips. The participant did not make a selection of preferred items, and no programmed consequences were delivered to the participant. Again, the video procedure continued for the remaining four trials of the session, with 5s delay for acceptance or approach, and 30s delay for consumption.

\section{Video modeling of differential reinforcement plus differential reinforcement (VM of}

DR + DR). A green placemat was used during VM of DR + DR sessions. Whereas only the model contacted DR in the previous phase, the participant also had the potential to contact the contingency in this phase. The procedures and video clips for this phase were the same as the previous, except as follows: before presenting the video clip, the PI prompted the participant to choose a preferred edible or tangible from all items determined as preferred during assessment; and each time the participant consumed a bite of the target food, the PI provided a praise statement and delivered the chosen preferred item immediately after mouth check. If the participants chose edibles, a larger bite (approximately $3 \mathrm{~cm}$ by $3 \mathrm{~cm}$ ) was provided. If the participant chose a tangible, 30s of access was provided. If the participant manded for an alternative preferred item during a session, that edible or tangible was provided. No programmed consequences were provided for IMB.

Video modeling of differential reinforcement/non-removal of spoon plus differential reinforcement (VM of DR/NRS + DR). A white placemat was used during VM of DR/NRS + DR sessions. If the mastery criterion was not met in previous phases, EE procedures were implemented with the model only. In this phase, procedures for the target food were the same as the previous phase, except the PI played the video for DR/NRS. In this video, after the model 
selected a preferred item and was presented with the target food, he displayed IMB similar to behavior the participant had displayed in previous sessions for 30s. The PI implemented NRS by holding a spoon of the target food close to the model's lips. After 30s of IMB, the model opened his mouth to accept the food from the spoon. The model then received the programmed reinforcement for consumption. After the DR/NRS video, the PI continued procedures to wait for approach, acceptance or consumption from the participant as in previous phases. If the participant consumed the bite of food, the preferred item was delivered after mouth check, regardless of any IMB. NRS was not implemented with the participant: if he did not consume the food, the PI removed the plate and continued procedures for the next trial.

Generalization probes. Generalization probes were completed prior to and after intervention to assess whether treatment effects generalized to a novel person. The procedures for these probes were similar to baseline: no programed consequences were delivered; the parent presented five bites of the target food to the child and waited 5s for approach or acceptance; and the parent removed the plate after $5 \mathrm{~s}$ with no approach or acceptance, or when the bite was consumed.

Social validity. Social validity was assessed using a questionnaire (see Appendix E) delivered to parents after watching video clips of their child. Parents watched video clips of one randomly selected baseline session and one randomly selected session from the phase in which the child met mastery criterion. The questionnaire included a 5-point Likert-type scale from 1 (strongly disagree) to 5 (strongly agree) with questions related to general acceptability of procedures and the effects of the intervention. 


\section{Results}

\section{Pre-Assessments}

Preference assessments. For Billy, preferred activities as identified through the preference assessment included tickles and the Alvin and the Chipmunk's Christmas Time song. Skittles, Hershey's chocolate bars, raisins, and strawberries were identified as preferred foods, and cookies, dried papayas, dried pineapples, dried bananas, and black beans were identified as nonpreferred foods. Based on parent selection, dried pineapple (Food A) and dried papaya (Food B) were selected as target foods during treatment evaluation.

For Elton, preferred activities included a light-up ball and an Angry Birds phone game. Preferred foods included Cheddar Cheese Pringles, Sour Cream and Onion Pringles, and jelly beans. Nonpreferred foods included strawberries, pears, broccoli, peanuts, and green beans. Based on parent selections, strawberries (Food A), broccoli (Food B), and pears (Food C) were targeted during treatment evaluation.

Only one preferred tangible was identified for Oscar: a toy car. Skittles, peanuts, cashews and raisins were identified as preferred foods. Broccoli, green beans, pitted black olives, and sweet pickles were identified as nonpreferred foods. Based on parent selection green beans (Food A), black olives (Food B), and broccoli (Food C) were targeted during treatment evaluation.

Pre-requisite skills. Billy responded correctly on $100 \%$ of trials in both sessions of the delayed imitation of actions with objects assessment. On the delayed picture-to-object match to sample assessment, Billy scored $88.9 \%$ in both sessions. During the initial delayed computer picture-to-object match to sample assessment, Billy scored 55.6\% in Session 1 and $66.7 \%$ in 
Session 2. When change of preferred item was allowed as per participant manding, Billy's scores increased on this assessment to $88.9 \%$ for both sessions. Billy also scored $100 \%$ on the attending to video assessment.

Elton responded correctly on $88.9 \%$ of trials during Session 1 and $100 \%$ of trials during Session 2 of the delayed imitation of actions with objects assessment. For both delayed pictureto-object match to sample and delayed computer picture-to-object match to sample assessments, Elton scored $100 \%$ on both sessions. Elton also scored $100 \%$ on the attending to video assessment.

On the initial delayed imitation of actions with objects assessment, Oscar responded correctly on $88.9 \%$ of trials during Session 1 and $66.7 \%$ of trials during session 2. After specific instruction that throwing the ball would not be rewarded with preferred items, the PI repeated Session 2 and Oscar's score increased to $88.9 \%$. A similar instruction was provided prior to the delayed picture-to-object match to sample assessment. Oscar scored 100\% and 77.8\% for Sessions 1 and 2, respectively, on this assessment. Oscar scored 88.9\% and 100\% for Sessions 1 and 2, respectively, of the delayed computer picture-to-object match to sample assessment. Finally, Oscar scored $100 \%$ on the attending to video assessment.

\section{Treatment Evaluation}

Figures 1, 2, and 3 depict the results for treatment evaluation of Food A, Food B, and Food C (Elton and Oscar only) across the three participants for acceptance, consumption, and IMB, respectively. Figures 4, 5, and 6 depict the results for generalization probes for acceptance, consumption and IMB, respectively, for Food A and Food B. Figures 7, 8, and 9 depict the results for generalization probes for acceptance, consumption and IMB, respectively, for Food C. 
Billy. Billy accepted and consumed Foods A and B when VM of DR + DR was introduced (top panel of Figures 1 and 2). Billy's acceptance of Food A was between $0 \%$ and $40 \%$ of trials per session and consumption was at $0 \%$ of trials per session until the VM of DR + DR phase was implemented, at which point acceptance and consumption immediately increased to $100 \%$ for three consecutive sessions. These results were replicated with Food B: acceptance and consumption of Food B was at $0 \%$ until the VM of DR + DR treatment was implemented with Food B, at which point acceptance and consumption immediately increased to $100 \%$ for three consecutive sessions. When treatment was removed during post-mastery baseline probes, acceptance and consumption of Food A maintained at $80 \%$ and Food B at 100\%. IMB was at $80 \%$ to $100 \%$ for Food A and 100\% for Food B in baseline. When treatment was introduced with Food A, an immediate decrease in level and decreasing trend of IMB was observed, while IMB for Food B remained at $80 \%$ in VM and 100\% in VM of DR (top panel of Figure 3). When consumption increased to $100 \%$, IMB immediately decreased to $0 \%$ or $20 \%$ when Foods A and B were presented. These results maintained when treatment was removed.

Elton. Elton's acceptance and consumption of Foods A and C occurred with VM of DR + DR, while acceptance and consumption of Food B never occurred (middle panel of Figures 1 and 2). Elton's acceptance and consumption of Food A in baseline, VM, and VM or DR was at $0 \%$ of trials per session, except the first session of baseline in which acceptance occurred $20 \%$ of trials. When VM of DR + DR was implemented, acceptance and consumption met mastery criterion after seven treatment sessions. Results were not replicated with Food B: acceptance and consumption of Food B remained a 0\% across all phases. Acceptance and consumption of Food $\mathrm{C}$ was $0 \%$ in baseline probes. When the VM of DR + DR phase was implemented, acceptance and consumption immediately increased to $100 \%$ for three consecutive sessions. Results of Food 
$\mathrm{A}$ and Food $\mathrm{C}$ maintained when treatment was removed. By the third baseline session, IMB decreased from $80 \%$ to $0 \%$ and maintained at $0 \%$ or $20 \%$ through the remaining sessions across intervention phases (middle panel of Figure 3).

Oscar. For Oscar, acceptance and consumption of Food A occurred with VM but acceptance and consumption of Foods B and C occurred with VM of DR + DR (bottom panel of Figures 1 and 2). Oscar's acceptance and consumption of Food A immediately increased from $0 \%$ in baseline when the first VM treatment phase was implemented, meeting mastery criterion after five sessions. Results were not replicated with Food B: acceptance varied from 0\% to 40\% of trials per session, and consumption was stable at $0 \%$ until VM of DR + DR was implemented. Acceptance and consumption increased in the second treatment session to $100 \%$ for three consecutive sessions when VM of DR + DR was introduced. These results were replicated with Food C, as is demonstrated by low levels of acceptance and consumption until the VM of DR + DR phase, when an immediate increase to mastery criterion occurred for both behaviors. The improvements in acceptance and consumption for Food A did not maintain when treatment was removed. For Food B, acceptance was at $80 \%$ and consumption was at $0 \%$ during maintenance probes. When treatment was removed for Food C, 100\% acceptance and consumption maintained. An increasing trend in IMB was observed during the second half of baseline with Food A and Food B. When VM was implemented with Food A, IMB for both Food A and B immediately decreased to 0\% (bottom panel of Figure 3). For Food A, IMB was variable during post-mastery probes, ranging from $0 \%$ to $80 \%$ of trials. When treatment was implemented with Food B, variable levels of IMB were observed. IMB for Food C was 0\% through baseline probes and intervention until the VM of DR phase, at which point it increased to 20 to $80 \%$. 
Generalization probes. For Billy, pre- and post-generalization probes of acceptance and consumption for Food A and Food B increased from $0 \%$ to $60 \%$ and $0 \%$ to $100 \%$, respectively (Figures 4 and 5). Pre- and post-generalization probes for IMB showed a decrease from 100\% to 0\% for both foods (Figure 6).

For Elton, pre- and post-generalization probes of acceptance and consumption for Food A and Food C increased from $0 \%$ to $80 \%$ and $0 \%$ to $100 \%$, respectively. Acceptance and consumption of Food B occurred during 0\% of trials of both generalization probes (Figures 4, 5, 7 and 8). IMB was also low during pre-and post-generalization probes across all foods (Figures 6 and 9).

For Oscar, pre-and post-generalization probes of acceptance and consumption for Food A and Food C increased from $0 \%$ to $100 \%$ of trials per session. For Food B, an increase from $0 \%$ to $20 \%$ of trials accepted was observed from pre- to post-generalization probes, while consumption of Food B remained at 0\% during both probes (Figures 4, 5, 7 and 8). IMB was not observed during pre- and post-generalization probes for Food A or Food C. IMB for Food B increased from $20 \%$ of trials during the pre-generalization probe to $40 \%$ of trials during the postgeneralization probe (Figures 6 and 9).

Social validity. All participants' parents rated the intervention the maximum score of 25 , indicating they approved of the procedures, found the intervention effective, would continue to use the intervention with their children, and believed they could implement the intervention if provided with training. 


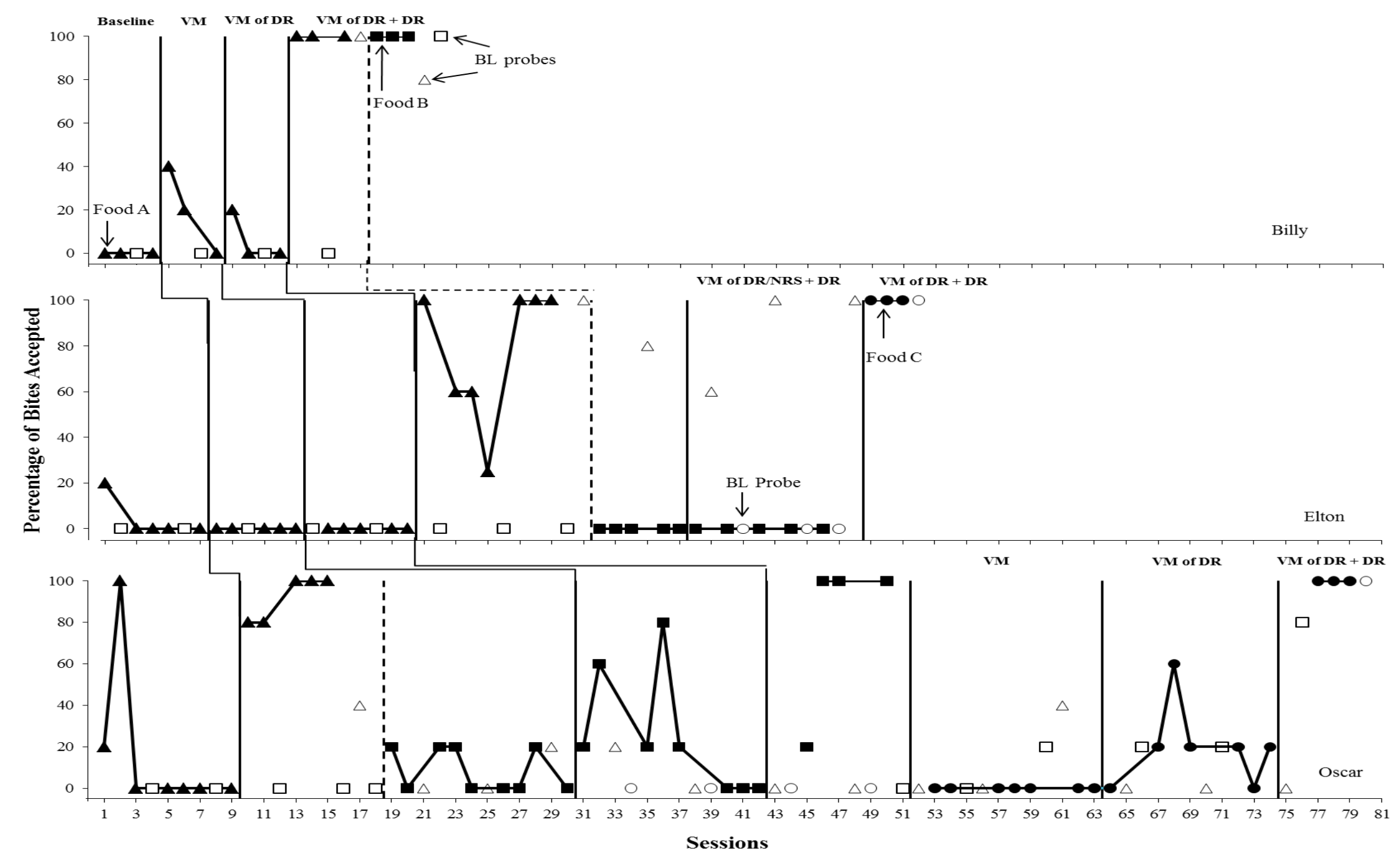

Figure 1. The percentage of bites accepted for Food A (triangles), Food B (squares), and Food C (circles) are displayed for Billy (top panel), Elton (middle panel), and Oscar (bottom panel). Solid shapes represent the food in treatment and open shapes represent baseline probes. 


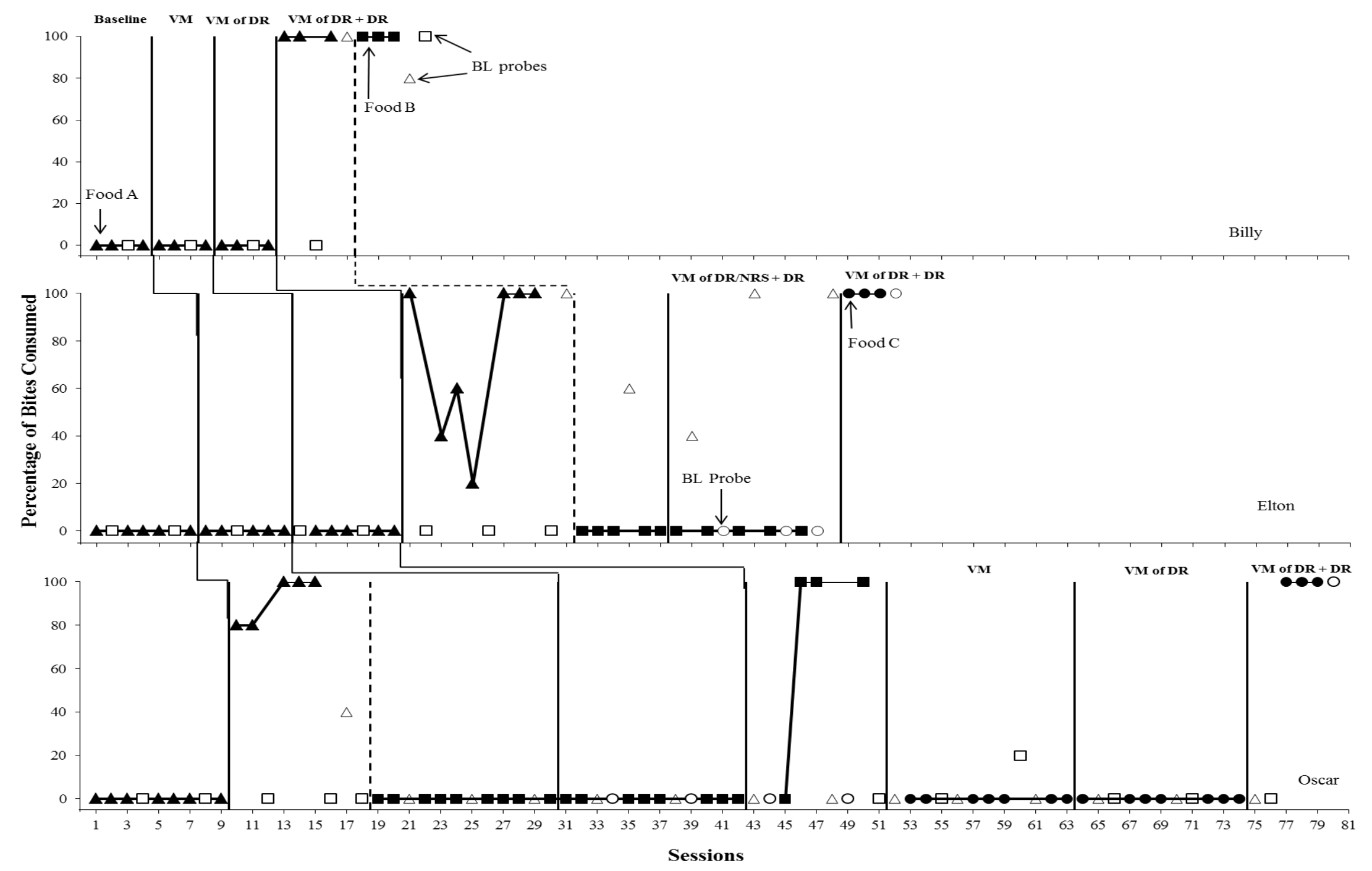

Figure 2. The percentage of bites consumed for Food A (triangles), Food B (squares) and Food C (circles) are displayed for Billy (top panel), Elton (middle panel), and Oscar (bottom panel). Solid shapes represent the food in treatment and open shapes represent baseline probes. 


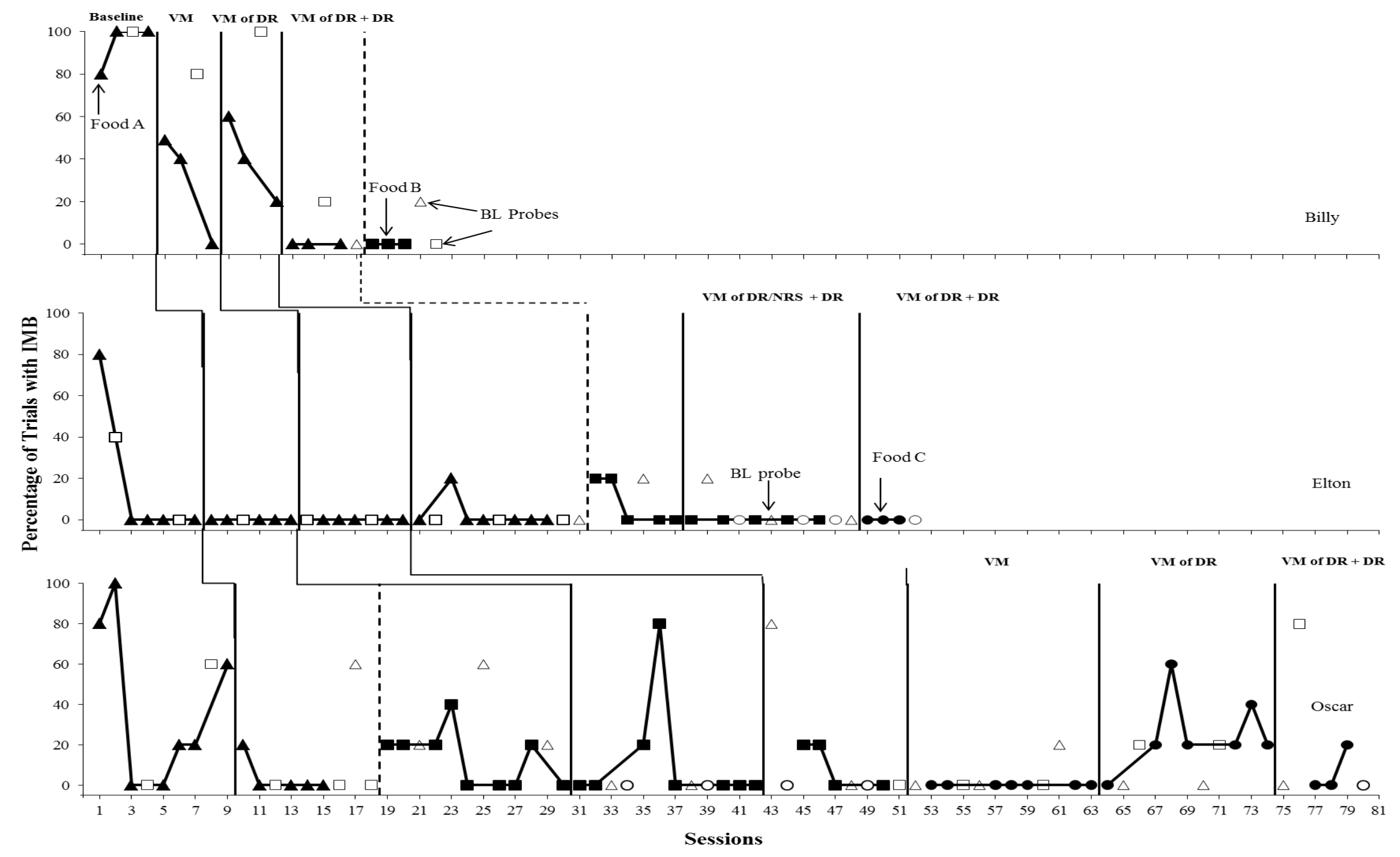

Figure 3. The percentage of trials with IMB is displayed for Billy (top panel), Elton (middle panel), and Oscar (bottom panel). Triangles represent Food A, squares represent Food B, and circles represent Food C. Solid shapes represent the food in treatment and open shapes represent baseline probes. 


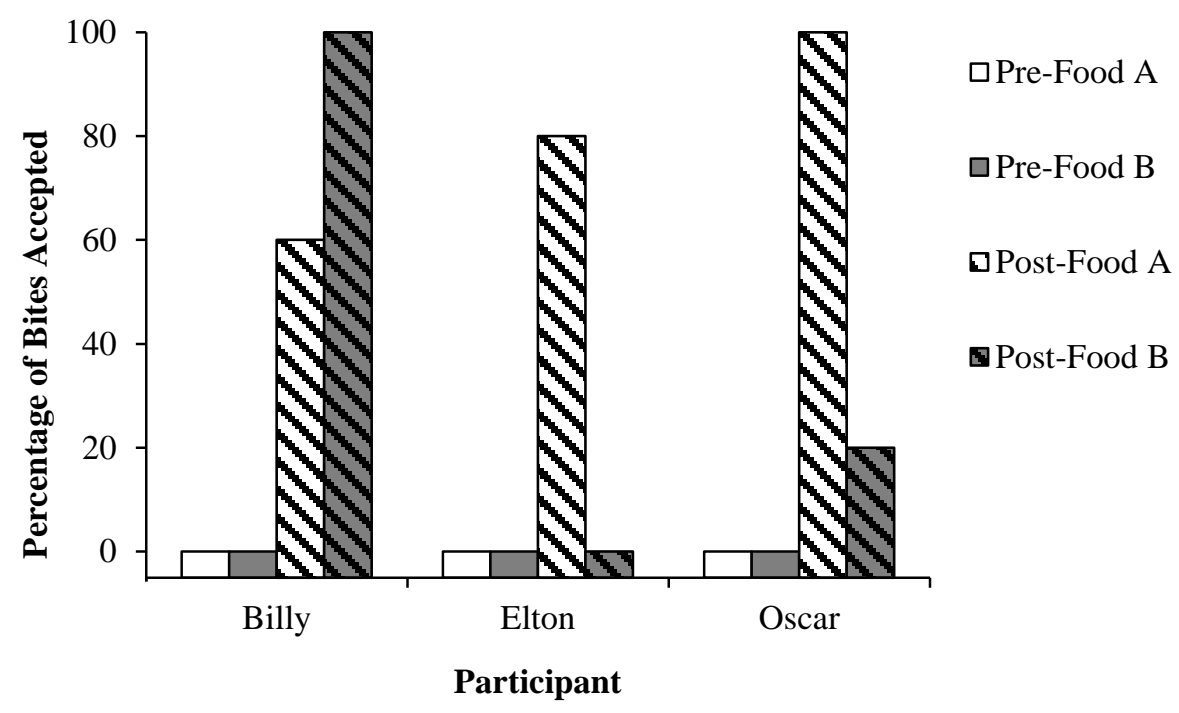

Figure 4. The percentage of bites accepted during generalization probes is displayed for Billy (left), Elton (middle) and Oscar (right). White bars represent Food A and grey bars represent Food B. Solid bars represent pre-generalization probes and stripped bars represent postgeneralization probes.

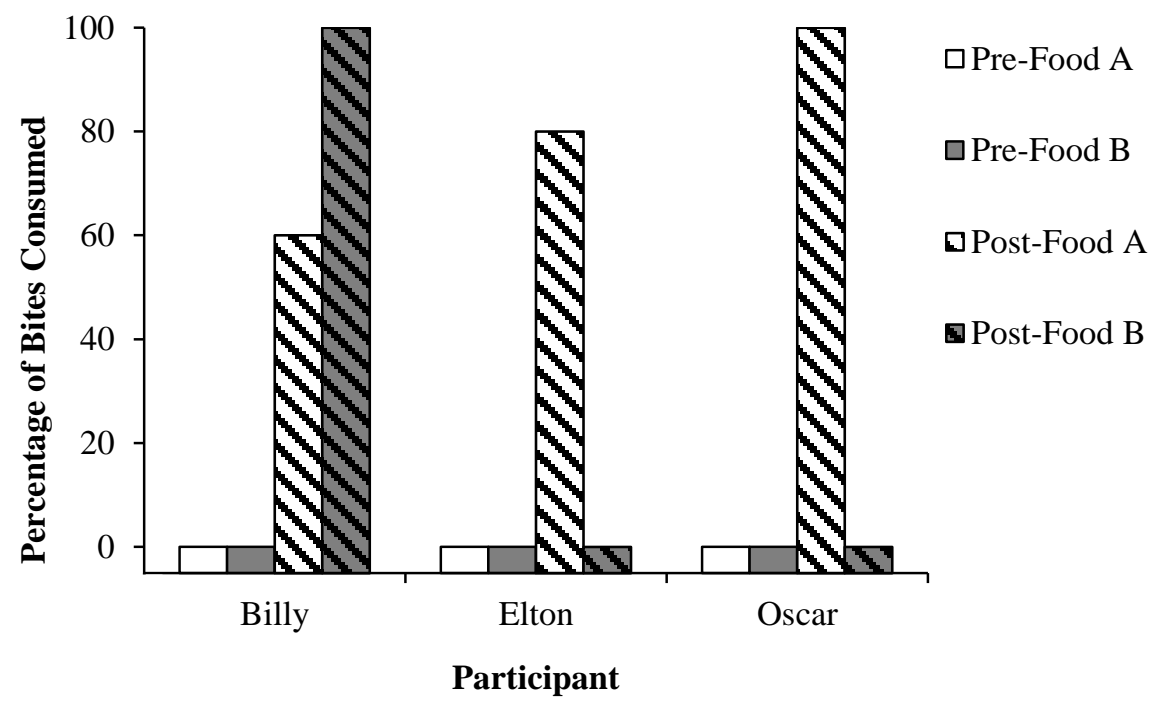

Figure 5. The percentage of bites consumed during generalization probes is displayed for Billy (left), Elton (middle) and Oscar (right). White bars represent Food A and grey bars represent Food B. Solid bars represent pre-generalization probes and stripped bars represent postgeneralization probes. 


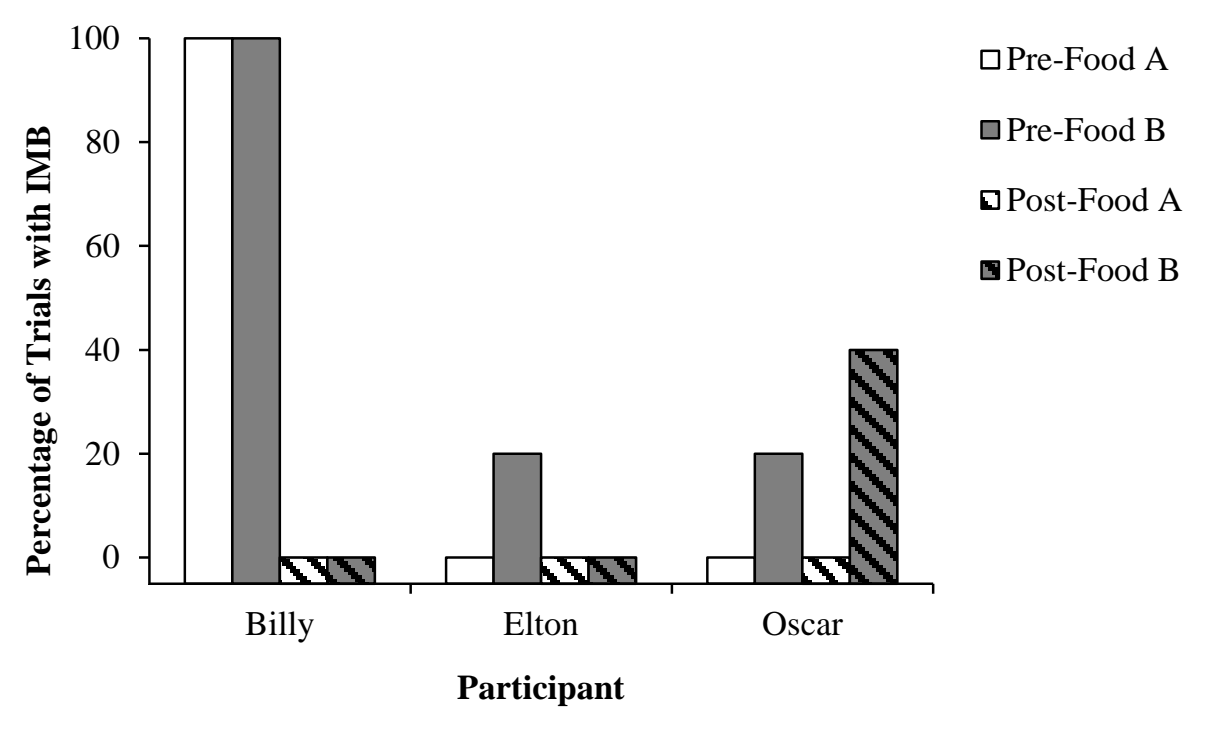

Figure 6. The percentage of trials with IMB during generalization probes is displayed for Billy (left), Elton (middle) and Oscar (right). White bars represent Food A and grey bars represent Food B. Solid bars represent pre-generalization probes and stripped bars represent postgeneralization probes.

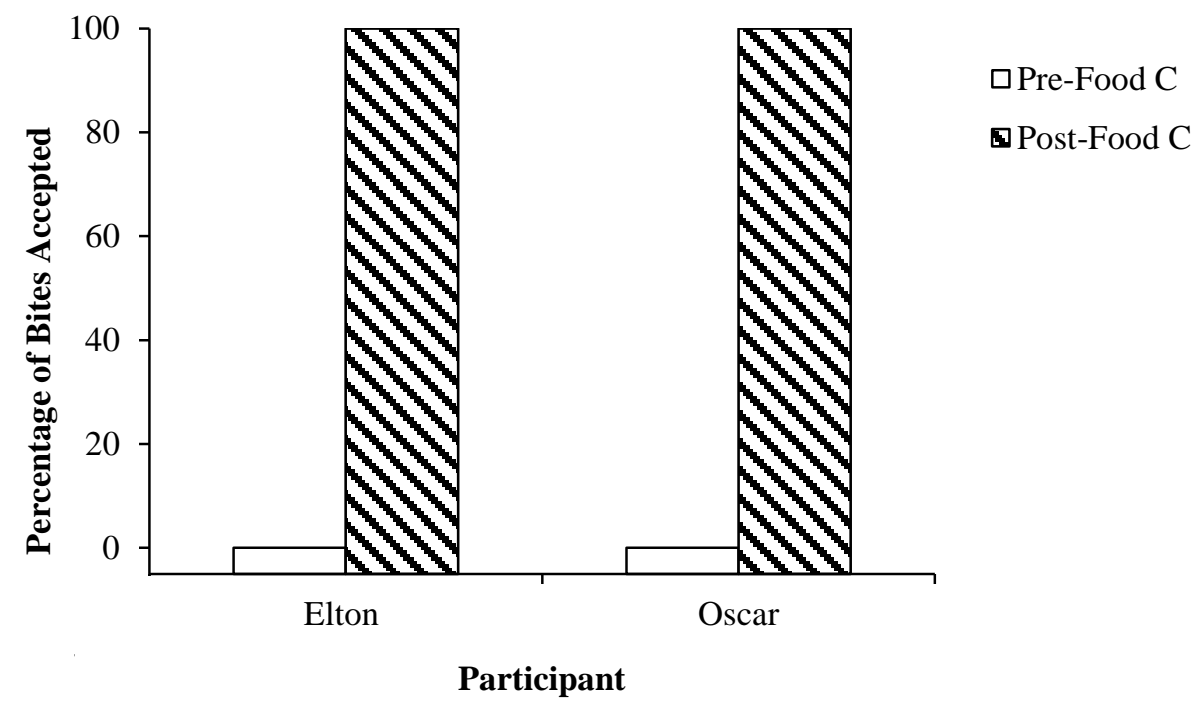

Figure 7. The percentage of bites accepted during generalization probes for Food C is displayed for Elton (left) and Oscar (right). White bars represent pre-generalization probes and stripped bars represent post-generalization probes. 


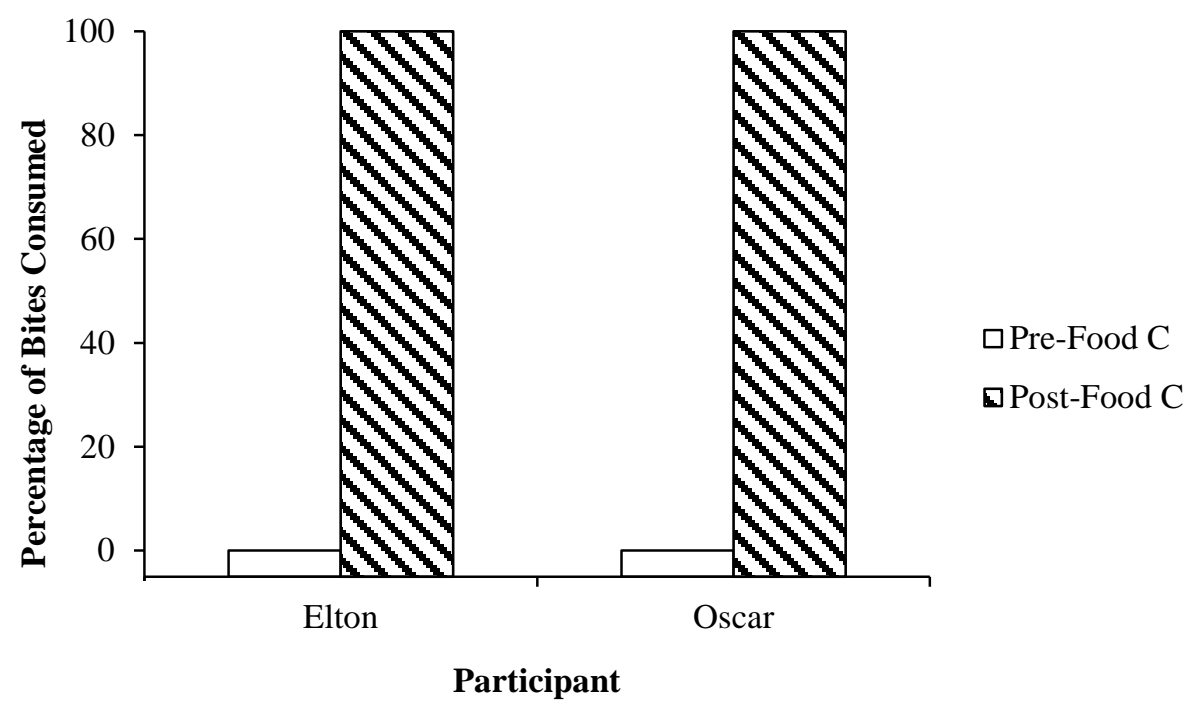

Figure 8. The percentage of bites consumed during generalization probes for Food $\mathrm{C}$ is displayed for Elton (left) and Oscar (right). White bars represent pre-generalization probes and stripped bars represent post-generalization probes.

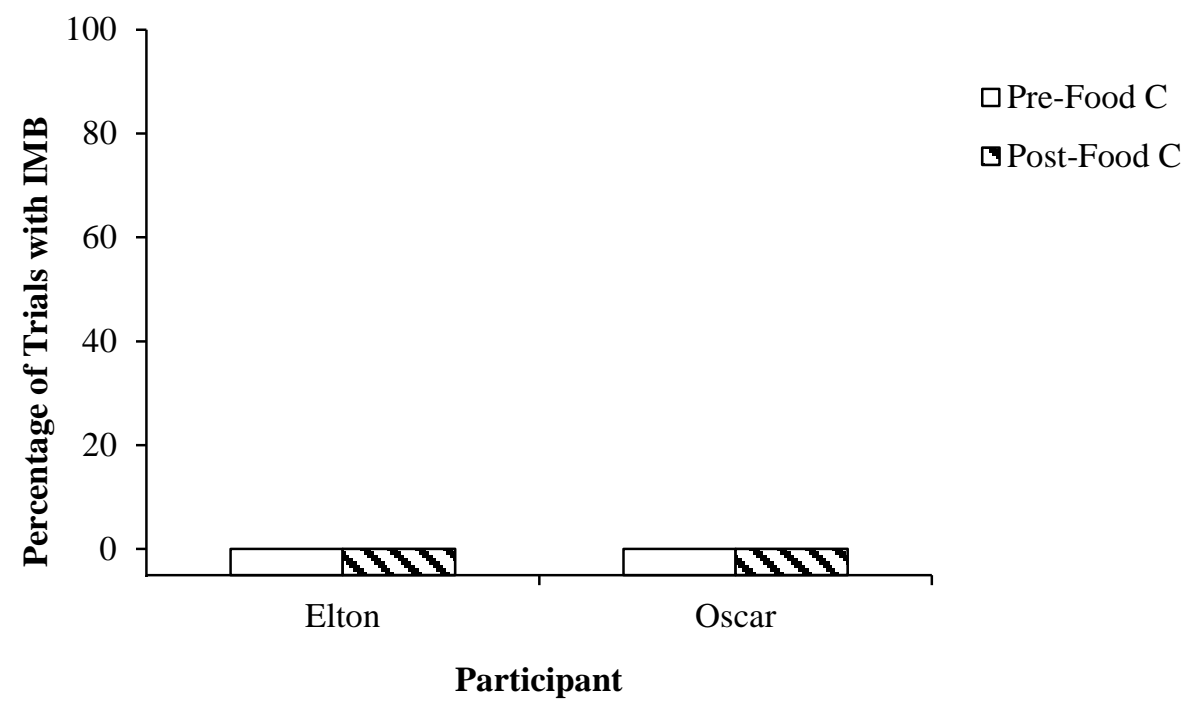

Figure 9. The percentage of trials with IMB during generalization probes for Food $\mathrm{C}$ is displayed for Elton (left) and Oscar (right). White bars represent pre-generalization probes and stripped bars represent post-generalization probes. 


\section{Discussion}

This study evaluated the extent to which VM of contingency procedures impacted acceptance and consumption of nonpreferred foods. VM and VM of DR were evaluated sequentially as antecedent interventions, as previous studies evaluated in-vivo modeling as part of treatment packages implemented after participants refused food. Overall, the results indicate that an intervention with VM of contingencies plus exposure to DR may increase consumption of most foods. Generally, exposure to reinforcement was a necessary component of the intervention, indicating the antecedent interventions of VM and VM of contingencies were not effective alone. All participants demonstrated improvement in acceptance and consumption of two foods when exposed to VM of DR + DR. Across participants, seven of the eight target foods met mastery criterion during one of the treatment phases. Six of these seven foods met the criterion in the VM of DR + DR phase. One food for Oscar met mastery criterion in VM alone. However, it should be noted that these results did not generalize to a second food with this participant, and behavioral outcomes did not maintain. It is hypothesized that the initial novelty of the treatment videos caused an increase in consumption of Food A, but this novelty wore off by the presentation of the second food and additional reinforcement may have been needed to maintain results. One food for Elton never met mastery criterion after sequential implementation of all treatments. The treatment effects maintained for at least one post-mastery probe for two of two foods for Billy and Elton, and one of two foods for Oscar. However, post-mastery probes for Elton's Food A were variable. The results for IMB were inconclusive as data were not replicated across participants: a decreasing trend was observed for Billy during treatment phases; 
IMB for Elton was low through all treatment phases; and Oscar engaged in variable levels of IMB throughout the study. Results of generalization probes for all participants indicated treatment effects generalized to a novel person for Foods A and C, but less so for Food B.

These results are consistent with research that demonstrated increased consumption of nonpreferred food only when modeling and exposure to DR were combined (e.g., Greer et al., 1991; Sira \& Fryling, 2012). However, unlike Fu et al. (2015), modeling of EE procedures (i.e., $\mathrm{VM}$ of DR/NRS + DR) was not found effective for Elton. Similar to the results found by Seiverling et al. (2014), direct exposure to EE may have been necessary to increase Elton's consumption of Food B. It is also hypothesized that the magnitude of reinforcement provided contingent on consumption might not have been great enough to overcome the aversiveness of consuming this novel food for Elton.

The results of this study make sense in terms of basic behavioral principles. That antecedent interventions involving VM were not effective should not be surprising as no reinforcement contingencies were in place to strengthen acceptance and consumption. In this study, acceptance and consumption did not occur in baseline, as the target foods did not function as reinforcers, and did not occur in VM phases when no reinforcers were programmed. Although modeling may evoke a target behavior, reinforcement is required to strengthen and thus maintain the behavior (Miltenberger, 2016). The data for Billy's acceptance seem to show that the VM procedures initially evoked the behavior, but the behavior did not continue to occur, presumably because no reinforcement was programmed for the behavior. It was not until reinforcement contingencies were put in place for the behaviors in the VM of DR + DR phases that the behaviors increased and occurred consistently. 
Participants' history with food selectivity treatment may also have impacted results. For example, Oscar initially accepted Food A 20\% and 100\% of trials during the first two baseline sessions. These results may be due to previously implemented interventions for food selectivity that included reinforcement (e.g., praise) contingent on accepting novel foods, according to parent report. The increase to $100 \%$ acceptance may represent an extinction burst as acceptance no longer resulted in reinforcement. Interestingly, consumption did not occur along with acceptance during these initial baseline sessions.

One limitation of this study is that scoring IMB as an occurrence or nonoccurrence per trial was not a sensitive measure. This method of data collection may overestimate the total level of IMB. Because one instance of IMB per trial was summarized as $100 \%$, the results could be misinterpreted as IMB occurring throughout the entire session, when it only occurred for five brief instances. Moreover, any IMB that may have occurred between trials was not scored; only IMB that occurred during trails was recorded (i.e., only when the plate of food was in front of the participant). Perhaps a duration measure of IMB would have produced a better picture of how much IMB occurred throughout the sessions.

Another limitation of this study is that only participants who scored highly on prerequisite skills assessments, approximately $80 \%$, were included as it was hypothesized that these participants would learn quickly from video modeling (MacDonald et al., 2015). It is unknown if individuals who score lower on these assessments would perform similarly. Thus, future research may evaluate these procedures with participants of varied skill levels to determine which individuals are likely to benefit from the intervention.

Another limitation in this study is the absence of long-term data on maintenance. It is not known how long these procedures would continue to be effective. Researchers should measure 
the effects of these procedures over time and if needed, evaluate methods to promote maintenance after increased consumption.

As replication was not demonstrated across all foods, more research is needed to determine the effectiveness of the different interventions in this study. VM procedures were evaluated in this study because they may be more efficient than in-vivo modeling procedures (e.g., Charlop-Christy et al., 2000). However, this study did not compare VM and in-vivo modeling. Additionally, it is unknown how the results demonstrated with VM of contingency procedures would compare to DR alone. Future research is needed to evaluate the effectiveness of a DR contingency alone compared to VM of contingencies plus DR procedures in the treatment of food selectivity.

In conclusion, this study demonstrated that the antecedent interventions of VM and VM of contingencies, with one exception, were not effective for increasing food acceptance or consumption across three participants and foods. The intervention that was effective involved the actual implementation of DR contingencies to strengthen the target behaviors. Because antecedent interventions such as VM are efficient and accessible, more research should evaluate the parameters of such interventions to identify when and with whom they are effective. 


\section{References}

Acar, C., \& Diken, I. H. (2012). Reviewing instructional studies conducted using video modeling to children with autism. Educational Sciences: Theory and Practice, 12, 2731-2735.

Ahearn, W. H. (2002). Effect of two methods of introducing foods during feeding treatment on acceptance of previously rejected items. Behavioral Interventions, 17, 111-127.

Ahearn, W. H., Kerwin, M., Eicher, P. S., Shantz, J., \& Swearingin, W. (1996). An alternating treatments comparison of two intensive interventions for food refusal. Journal of Applied Behavior Analysis, 29, 321-332.

Allison, J., Wilder, D. A., Chong, I., Lugo, A., Pike, J., \& Rudy, N. (2012). A comparison of differential reinforcement and noncontingent reinforcement to treat food selectivity in a child with autism. Journal of Applied Behavior Analysis, 45, 613-617.

Bachmeyer, M. H. (2009). Treatment of selective and inadequate food intake in children: A review and practical guide. Behavior Analysis in Practice, 2, 43-50.

Bachmeyer, M. H., Piazza, C. C., Fredrick, L. D., Reed, G. K., Rivas, K. D., \& Kadey, H. J. (2009). Functional analysis and treatment of multiply controlled inappropriate mealtime behavior. Journal of Applied Behavior Analysis, 42, 641-658.

Bandini, L. G., Anderson, S. E., Curtin, C., Cermak, S., Evans, E. W., Scampini, R.,...Must, A. (2010). Food selectivity in children with autism spectrum disorders and typically developing children. The Journal of Pediatrics, 157, 259-264.

Bellini, S., \& Akullian, J. (2007). A meta-analysis of video modeling and video self-modeling 
interventions for children and adolescents with autism spectrum disorders. Council for Exceptional Children, 73, 264-287.

Bidwell, M. A., \& Rehfeldt, R. A. (2004). Using video modeling to teach a domestic skill with an embedded social skill to adults with severe mental retardation. Behavioral Interventions, 19, 263-274.

Borrero, C. S., Schlereth, G. J., Rubio, E. K., \& Taylor, T. (2013). A comparison of two physical guidance procedures in the treatment of pediatric food refusal. Behavioral Interventions, $28,261-280$.

Boudreau, E., \& D'Entremont, B. (2010). Improving the prentend play skills of preschoolers with autism spectrum disorders: The effects of video modeling. Journal of Developmental and Physical Disabilities, 22, 415-431.

Buckley, S. D., \& Newchok, D. K. (2005). An evaluation of simultaneous presentation and differential reinforcement with response cost to reduce packing. Journal of Applied Behavior Analysis, 38, 405-409.

Cardon, T. A., Guimond, A., \& Smith-Treadwell, A. M. (2015). Video modeling and children with autism spectrum disorder: A survey of caregiver perspectives. Education and Treatment of Children, 38, 403-420.

Charlop-Christy, M. H., Le, L., \& Freeman, K. A. (2000). A comparison of video modeling with in vivo modeling for teaching children with autism. Journal of Autism and Developmental Disorders, 30, 537-552.

Cooper, L. J., Wacker, D. P., McComas, J. J., Brown, K., Peck, S., M., Richman, D.,...Millard, T. (1995). Use of component analyses to identify active variables in treatment packages for children with feeding disorders. Journal of Applied Behavior Analysis, 28, 139-153. 
DeMeyer, M. K. (1979). Parents and children in autism. New York: Wiley.

Fisher, W.W. Piazza, C.C., Bowman, L.G., \& Amari, A. (1996). Integrating caregiver report with a systematic choice assessment. American Journal on Mental Retardation, 101, 1525.

Fisher, W. W., Piazza, C. C., Bowman, L. G., Hagopian, L. P., Owens, J. C., \& Slevin, I. (1992). A comparison of two approaches for identifying reinforcers for persons with severe and profound disabilities. Journal of Applied Behavior Analysis, 25, 491-498.

Fu, S. B., Penrod, B. Fernand, J. K., Whelan, C. M., Griffith, K., \& Medved, S. (2015). The effects of modeling contingencies in the treatment of food selectivity in children with autism. Behavior Modification, 39, 771-784.

Girolami, P. A., Boscoe, J. H., Roscoe, N. (2007). Decreasing expulsions by a child with a feeding disorder: Using a brush to present and re-present food. Journal of Applied Behavior Analysis, 40, 749-753.

Greer, R. D., Dorow, L., Williams, G., McCorkle, N., \& Anes, R. (1991). Peer-mediated procedures to induce swallowing and food acceptance in young children. Journal of Applied Behavior Analysis, 24, 783-790.

Hoch, T. A., Babbitt, R. L., Coe, D. A., Krell, D. M., \& Hackbert, L. (1994). Contingency contacting: Combining positive reinforcement and escape extinction procedures to treat persistent food refusal. Behavior Modification, 18, 106-128.

Hoch, T. A., Babbitt, R. L., Farrar-Schneider, D., Berkowitz, M. J., Owens, J. C., Knight, T. L.,...Wise, D. T. (2001). Empirical examination of a multicomponent treatment for pediatric food refusal. Education and Treatment of Children, 24, 176-198.

Kern, L., \& Marder, T. J. (1996). A comparison of simultaneous and delayed reinforcement as 
treatments for food selectivity. Journal of Applied Behavior Analysis, 29, 243-246.

Kerwin, M. E. (1999). Empirically supported treatments in pediatric psychology: Severe feeding problems. Journal of Pediatric Psychology, 24, 193-214.

LaRue, R. H., Stewart, V., Piazza, C. C., Volkert, V. M., Patel, M. R., \& Zeleny, J. (2011).

Escape as reinforcement and escape extinction in the treatment of feeding problems. Journal of Applied Behavior Analysis, 44, 719-735.

Lerman, D., C., Iwata, B., A., \& Wallace, M. D. (1999). Side effects of extinction: Prevalence of bursting and aggression during the treatment of self-injurious behavior. Journal of Applied Behavior Analysis, 32, 1-8.

Levin, L., \& Carr, E. G. (2001). Food selectivity and problem behavior in children with developmental disabilities: Analysis and intervention. Behavior Modification, 25, 443470.

Luiselli, J. K., Ricciardi, J. N., \& Gilligan, K. (2005). Liquid fading to establish milk consumption by a child with autism. Behavioral Interventions, 20, 155-163.

MacDonald, R. P. F., Dickson, C. A., Martineau, M., \& Ahearn, W. H. (2015). Prerequisite skills that support learning through video modeling. Education and Treatment of Children, 38, $33-48$.

Mason, R. A., Ganz, J. B., Parker, R. I., Burke, M. D., \& Camargo, S. P. (2012). Moderationg factors of video-modeling with other as model: A meta-analysis of single-case studies. Research in Developmental Disabilities, 33, 1076-1086.

Meier, A. E., Fryling, M. J., \& Wallace, M. D. (2012). Using high-probability foods to increase the acceptance of low-probability foods. Journal of Applied Behavior Analysis, 45, 149153. 
Miltenberger, R.G., (2016). Behavior modification: Principles and procedures (6th Ed.). Boston, MA: Cengage.

Nikopoulos, C. K., \& Keenan, M. (2003). Promoting social initiation in children with autism using video modeling. Behavioral Interventions, 18, 87-108.

Patel, M. R., Piazza, C. C., Kelly, M. L., Ochsner, C. A., \& Santana, C. M. (2001). Using a fading procedure to increase fluid consumption in a child with feeding problems. Journal of Applied Behavior Analysis, 34, 357-360.

Patel, M., Reed, G. K., Piazza, C. C., Mueller, M., Bachmeyer, M. H., \& Layer, S. A. (2007). Use of high-probability instructional sequence to increase compliance to feeding demands in the absence of escape extinction. Behavioral Interventions, 22, 305-310.

Penrod, B., Gardella, L., \& Fernand, J. (2012). An evaluation of a progressive high-probability instructional sequence combined with low-probability demand fading in the treatment of food selectivity. Journal of Applied Behavior Analysis, 45, 527-537.

Perske, R., Clifton, A, McClean, B. M., \& Stein, J. I. (Eds.). (1977). Mealtimes for severely and profoundly handicapped persons: New concepts and attitudes. Baltimore, MD: University Park Press.

Piazza, C. C., Patel, M. R., Gulotta, C. S., Sevin, B. M., \& Layer, S. A. (2003). On the relative contributions of positive reinforcement and escape extinction in the treatment of food refusal. Journal of Applied Behavior Analysis, 36, 309-324.

Piazza, C. C., Patel, M. R., Santana, C. M., Goh, H., Delia, M. D., \& Lancaster, B. M. (2002). An evaluation of simultaneous and sequential presentation of preferred and nonpreferred food to treat food selectivity. Journal of Applied Behavior Analysis, 35, 259-270.

Plavnicak, J. B. (2012). A practical strategy for teaching a child with autism to attend to and 
imitate a portable video model. Research \& Practice for Persons with Severe Disabilities, 37, 263-270.

Reed, G. K., Piazza, C. C., Patel, M. R., Layer, S. A., Bachmeyer, M. H., Bethke, S. D., \& Gutshall, K. A. (2004). On the relative contributions of noncontingent reinforcement and escape extinction in the treatment of food refusal. Journal of Applied Behavior Analysis, 37, 27-42.

Riordan, M. M., Iwata, B. A., Finney, J. W., Wohl, M. K., \& Stanley, A. E. (1984). Behavioral assessment and treatment of chronic food refusal in handicapped children. Journal of Applied Behavior Analysis, 17, 327-341.

Riordan, M. M., Iwata, B. A., Wohl, M. K., \& Finney, J. W. (1980). Behavioral treatment of food refusal and selectivity in developmentally disabled children. Applied Research in Mental Retardation, 1, 95-112.

Schreck, K. A., Williams, K., \& Smith, A. F. (2004). A comparison of eating behaviors between children with and without autism. Journal of Autism and Developmental Disorders, 34, 433-438.

Seiverling, L., Harclerode, W., \& Williams, K. (2014). The effects of a modified treatment package with and without feeder modeling on one child's acceptance of novel foods. Education and Treatment of Children, 37, 477-494.

Seubert, C., Fryling, M. J., Wallace, M. D., Jiminez, A. R., \& Meier, A. E. (2014). Antecedent interventions for pediatric feeding problems. Journal of Applied Behavior Analysis, 47, 449-453.

Sharp, W. G., Berry, R. C., McCracken, C., Nuhu, N. N., Marvel, E., Saulnier, C. A.,...Jaquess, 
D. L. (2013). Feeding problems and nutrient intake in children with autism spectrum disorders: A meta-analysis and comprehensive review of the literature. Journal of Autism and Developmental Disorders, 43, 2159-2173.

Sharp, W. G., Harker, S., \& Jaquess, D. L. (2010). Comparison of bite-presentation methods in the treatment of food refusal. Journal of Applied Behavior Analysis, 43, 739-743.

Sharp, W. G., \& Jaquess, D. L. (2009). Bite size and texture assessments to prescribe treatment for severe food selectivity in autism. Behavioral Interventions, 24, 157-170.

Sharp, W. G., Jaquess, D. L., Morton, J. F., \& Herzinger, C. V. (2010). Pediatric feeding disorders: A quantitative synthesis of treatment outcomes. Clinical Child and Family Psychology Review, 13, 348-365.

Shore, B. A., Babbitt, R. L., Williams, K. E., Coe, D. A., \& Snyder, A. (1998). Use of texture fading in the treatment of food selectivity. Journal of Applied Behavior Analysis, 31, 621633.

Singer, L. T., Song, L., Hill, B. P., \& Jaffe, A. C. (1990). Stress and depression in mothers of failure-to-thrive children. Journal of Pediatric Psyhcology, 15, 711-720.

Sira, B. K., \& Fryling, M. J. (2012). Using peer modeling and differential reinforcement in the treatment of food selectivity. Education and Treatment of Children, 35, 91-100.

Tiger, J. H., \& Hanley. G. P. (2006). Using reinforcer pairing and fading to increase the milk consumption of a preschool child. Journal of Applied Behavior Analysis, 39, 399-403.

Wilder, D. A., Normand, M., \& Atwell, J. (2005). Noncontingent reinforcement as treatment for food refusal and associated self-injury. Journal of Applied Behavior Analysis, 38(4), 549553.

Wilkins, J. W., Piazza, C. C., Groff, R. A., Volkert, V. M., Kozisek, J. M., \& Milnes, S. M. 
(2014). Utensil manipulation during initial treatment of pediatric feeding problems.

Journal of Applied Behavior Analysis, 47, 694-709. 


\section{Appendices}




\section{Appendix A: Session Data Sheets}

Acceptance is defined as the participant placing the bite of target food in his/her mouth (past plane of lips using hands or utensil) within $5 \mathrm{~s}$ of prompt or after viewing the video.

Consumption is defined as participant swallows target food within 30s of acceptance as demonstrated by a mouth checks.

$\underline{\mathrm{IMB}}$ is denied as \{individually per participant\}

Instructions for research assistant:

Before beginning session, acquire appropriately colored placemat and target food items. If conducting VM of DR + DR, or VM of DR/NRS + DR acquire identified preferred edibles and/or tangibles.

Fill in date, target food, and preferred edible or item selected (if applicable).

Scoring:

- +: if acceptance and/or consumption (as defined above) occur

- --: if acceptance and/or consumption (as defined above) occur

- Place + if IMB (as defined above) occurs during OR - if no IMB occurs during the trial

\begin{tabular}{|c|c|c|c|c|c|}
\hline Date: & Target food: & Preferred Item: & & & \\
\hline \multicolumn{3}{|c|}{ Trial } & Acceptance & Consumption & IMB \\
\hline \multicolumn{3}{|c|}{1} & $+\quad-$ & $+\quad--$ & \\
\hline \multicolumn{3}{|c|}{2} & $+\quad--$ & $+\quad--$ & \\
\hline \multicolumn{3}{|c|}{3} & $+\quad--$ & $+\quad--$ & \\
\hline \multicolumn{3}{|c|}{4} & $+\quad--$ & $+\quad--$ & \\
\hline \multicolumn{3}{|c|}{5} & $+\quad--$ & $+\quad--$ & \\
\hline
\end{tabular}




\section{Appendix B: Treatment Integrity Checklists}

\section{Treatment Integrity Checklist: BL}

Approach is defined as reaching for, touching or picking up the target food, or similar behavior. Acceptance is defined as the participant placing the bite of target food in his/her mouth (past plane of lips using hands or utensil) within 5s of prompt or after viewing the video.

Consumption is defined as participant swallows target food within 30s of acceptance as demonstrated by a mouth checks.

\begin{tabular}{|l|l|}
\hline Step & \\
\hline 1. Blue placemat on table at start of session & Yes / No / NA \\
\hline 2. RA presented 1 bite of food per trial in front of participant & Yes / No / NA \\
\hline 3. RA presented vocal prompt "It's time to eat" or something similar & Yes / No / NA \\
\hline 4. RA waited 5s for approach or acceptance after presentation & Yes / No / NA \\
\hline 5. RA waited 5s for approach or acceptance after previous bite & Yes / No / NA \\
\hline$\bullet \quad$ If no approach or acceptance, RA removed plate of food & Yes / No / NA \\
\hline$\bullet \quad$ If approach or acceptance, RA waited up to 30s for consumption & Yes / No / NA \\
\hline$\bullet \quad$ If consumption, RA conducted mouth check & Yes / No / NA \\
\hline$\bullet \quad$ If no consumption, RA removed plate of food & Yes / No / NA \\
\hline 6. RA repeated steps 2-5 for 4 remaining trials & Yes / No / NA \\
\hline 7. No consequences (e.g., praise, preferred item, scolding) provided in session & Yes / No / NA \\
\hline
\end{tabular}

\section{Treatment Integrity Checklist: VM}

Approach is defined as reaching for, touching or picking up the target food, or similar behavior. Acceptance is defined as the participant placing the bite of target food in his/her mouth (past plane of lips using hands or utensil) within 5s of prompt or after viewing the video. Consumption is defined as participant swallows target food within 30s of acceptance as demonstrated by a mouth checks.

\begin{tabular}{|l|c|}
\hline Step & \\
\hline 1. Yellow placemat on table at start of session & Yes / No / NA \\
\hline 2. RA played video before presenting bite of food on each trial & Yes / No / NA \\
\hline 3. RA presented 1 bite of food per trial in front of participant & Yes / No / NA \\
\hline 4. RA presented vocal prompt "It's time to eat" or something similar & Yes / No / NA \\
\hline 5. RA waited 5s for approach or acceptance after presentation & Yes / No / NA \\
\hline$\bullet \quad$ If no approach or acceptance within 5s, RA removed plate & Yes / No / NA \\
\hline$\bullet \quad$ If approach or acceptance, RA waited up to 30s for consumption & Yes / No / NA \\
\hline$\bullet \quad$ If consumption, RA conducted mouth check & Yes / No / NA \\
\hline$\bullet \quad$ If no consumption, RA removed plate of food & Yes / No / NA \\
\hline 6. RA repeated steps 2-5 for 4 remaining trials & Yes / No / NA \\
\hline 7. No consequences (e.g., praise, preferred item, scolding) provided in session & Yes / No / NA \\
\hline
\end{tabular}


Approach is defined as reaching for, touching or picking up the target food, or similar behavior. Acceptance is defined as the participant placing the bite of target food in his/her mouth (past plane of lips using hands or utensil) within 5s of prompt or after viewing the video. Consumption is defined as participant swallows target food within 30s of acceptance as demonstrated by a mouth checks.

\begin{tabular}{|l|c|}
\hline Step & \\
\hline 1. Red placement on table at start of session & Yes / No / NA \\
\hline 2. RA played video before presenting bite of food on each trial & Yes / No / NA \\
\hline 3. RA presented 1 bite of food per trial in front of participant & Yes / No / NA \\
\hline 4. RA presented vocal prompt "It's time to eat" or something similar & Yes / No / NA \\
\hline 5. RA waited 5s for approach or acceptance after presentation & Yes / No / NA \\
\hline$\bullet \quad$ If no approach or acceptance, RA played video & Yes / No / NA \\
\hline$\bullet \quad$ If no approach or acceptance after video, RA removed plate of food & Yes / No / NA \\
\hline$\bullet \quad$ If approach or acceptance, RA waited up to 30s for consumption & Yes / No / NA \\
\hline$\bullet \quad$ If consumption, RA conducted mouth check & Yes / No / NA \\
\hline$\bullet \quad$ If no consumption, RA removed plate of food & Yes / No / NA \\
\hline 6. RA repeated steps 2-5 for 4 remaining trials & Yes / No / NA \\
\hline 7. No consequences (e.g., praise, preferred item, scolding) provided in session & Yes / No / NA \\
\hline
\end{tabular}

Treatment Integrity Checklist: VM of DR plus DR Approach is defined as reaching for, touching or picking up the target food, or similar behavior. Acceptance is defined as the participant placing the bite of target food in his/her mouth (past plane of lips using hands or utensil) within $5 \mathrm{~s}$ of prompt or after viewing the video.

Consumption is defined as participant swallows target food within 30s of acceptance as demonstrated by a mouth checks.

\begin{tabular}{|l|c|}
\hline Step & \\
\hline 1. Green placement on table at start of session & Yes / No / NA \\
\hline 2. RA prompted participant to select preferred edible/item and placed on table & Yes / No / NA \\
\hline 3. RA played video before presenting bite of food on each trial & Yes / No / NA \\
\hline 4. RA presented vocal prompt "It's time to eat" or something similar & Yes / No / NA \\
\hline 5. RA presented 1 bite of food per trial in front of participant & Yes / No / NA \\
\hline 6. RA waited 5s for approach or acceptance after presentation & Yes / No / NA \\
\hline$\bullet \quad$ If no approach or acceptance, RA played video & Yes / No / NA \\
\hline$\bullet \quad$ If no approach or acceptance after video, RA removed plate of food & Yes / No / NA \\
\hline$\bullet \quad$ If approach or acceptance, RA waited up to 30s for consumption & Yes / No / NA \\
\hline$\bullet \quad$ If consumption, RA conducted mouth check & Yes / No / NA \\
\hline$\bullet \quad$ If no consumption, RA removed plate of food & Yes / No / NA \\
\hline 7. If consumption, RA provided praise and participant's preferred item & Yes / No / NA \\
\hline 8. RA repeated steps 2-7 for 4 remaining trials & Yes / No / NA \\
\hline
\end{tabular}


Approach is defined as reaching for, touching or picking up the target food, or similar behavior. Acceptance is defined as the participant placing the bite of target food in his/her mouth (past plane of lips using hands or utensil) within $5 \mathrm{~s}$ of prompt or after viewing the video. Consumption is defined as participant swallows target food within 30s of acceptance as demonstrated by a mouth checks.

\begin{tabular}{|l|c|}
\hline Step & \\
\hline 1. White placement on table at start of session & Yes / No / NA \\
\hline 2. RA prompted participant to select preferred edible/item and placed on table & Yes / No / NA \\
\hline 3. RA played video before presenting bite of food on each trial & Yes / No / NA \\
\hline 4. RA presented vocal prompt "It's time to eat" or something similar & Yes / No / NA \\
\hline 5. RA presented 1 bite of food per trial front of participant & Yes / No / NA \\
\hline 6. RA waited 5s for approach or acceptance after presentation & Yes / No / NA \\
\hline$\bullet \quad$ If no approach or acceptance, RA played video & Yes / No / NA \\
\hline - If no approach or acceptance after video, RA removed plate of food & Yes / No / NA \\
\hline - If approach or acceptance, RA waited up to 30s for consumption & Yes / No / NA \\
\hline - If consumption, RA conducted mouth check & Yes / No / NA \\
\hline - If no consumption, RA removed plate of food & Yes / No / NA \\
\hline 7. If consumption, RA provided praise and participant's preferred item & Yes / No / NA \\
\hline 8. RA repeated steps 2-7 for 4 remaining trials & Yes / No / NA \\
\hline
\end{tabular}




\section{Appendix C: Reinforcement Assessment for Individuals with Severe Disabilities (RAISD)- adapted}

Participant's Name:

Date:

The purpose of this structured interview is to get as much specific information as possible from the informants (e.g., parent, caregiver) as to what they believe would be useful reinforcers for the participant as well as generate a list of nonpreferred foods they believe the participant does not consume. Therefore, this survey asks about categories of stimuli (e.g., visual, auditory, etc.). After the informant has generated a list of (non)preferred stimuli, ask additional probe questions to get more specific information on the participant's preferences and the stimulus conditions under which the object or activity is most/least preferred (e.g., What specific TV shows are his favorite? What does she do when she plays with a mirror? Does she prefer to do this alone or with another person? What specific vegetables are his least favorite?)

We would like to get some information on ___ 's preferences for different activities.

1. Some children really enjoy looking at things such as a mirror, bright lights, shiny objects, spinning objects, TV, etc. What are things you think most likes to watch?

Response(s) to probe questions:

2. Some children really enjoy different sounds such as listening to music, car sounds, whistles, beeps, sirens, etc. What are thing you thing most likes to listen to?

Response(s) to probe questions:

3. Some children really enjoy different smells such as perfume, flowers, coffee, pine trees, etc. What are the things you think most likes to smell?

Response(s) to probe questions:

4. Some children really enjoy certain foods or snacks such as ice cream, pizza, juice, graham crackers, McDonald's hamburgers, etc. What are the things you think most likes to eat?

Response(s) to probe questions: 
5. Some children really do not enjoy foods or snacks such as Brussel sprouts, salads, pineapple, coleslaw, cheeses, etc. What are the things you think likes to eat the least?

Response(s) to probe questions:

6. Some children really enjoy certain drinks such as fruit juice, smoothies, milkshakes, water etc. What are the things you think most likes to drink?

Response(s) to probe questions:

7. Some children really enjoy touching things of different temperatures, cold things like snow or an ice pack, or warm things like a hand warmer or a cup containing hot tea or coffee. What activities like this do you think most enjoys?

Response(s) to probe questions:

8. Some children really enjoy feeling different sensations such as splashing water in a sink, a vibrator against the skin, or the feel of air blown on the face from a fan. What activities like this do you think most enjoys?

Response(s) to probe questions:

9. Some children really enjoy toys or objects such as puzzles, toy cars, balloons, comic books, flashlight, bubbles, etc. What are 's favorite toys or objects?

Response(s) to probe questions:

10. What videos does most enjoy watching?

Response(s) to probe questions: 


\section{Appendix D: Video Modeling Screening Procedures (MacDonald et al., 2015)}

Delayed Imitation of Actions with Objects (two sessions, 18 trials)

Materials: common objects (e.g., cup, utensils, ball), pencil, data sheet

Instructions for research assistant

Present small bites of three preferred edibles to participant with statement "pick one". Provide the chosen edible for correct responses or after two consecutive incorrect responses.

Using the assigned object for the trial, say "do this" and complete one-step action with the object. Hold the object out of participant's view (e.g., under table) for 3s. Return the object to the table after $3 \mathrm{~s}$ and allow participant opportunity to complete action. Wait $5 \mathrm{~s}$ for the participant to respond, then remove object and set for next trial.

Scoring:

- $\quad+$ : if participant completes action independently within $5 \mathrm{~s}$, score +

- --: if the participant completes incorrect action within $5 \mathrm{~s}$, does not complete correct in $5 \mathrm{~s}$

- NR: if the participant does not respond within $5 \mathrm{~s}$

\begin{tabular}{|c|c|c|c|c|c|}
\hline & & Session: 1 & & & \\
\hline & & Date: & & & \\
\hline Starting position & Action & Object & & & \\
\hline Fork next to сир & Put fork in cup & 1 & + & -- & NR \\
\hline Ball next to plate & Put ball on top of plate & 2 & + & -- & NR \\
\hline Fork on top of plate & Put fork next to plate & 3 & + & -- & NR \\
\hline Ball next to сир & Put ball in cup & 4 & + & -- & NR \\
\hline Cup next to bowl & Put cup inside bowl & 5 & + & -- & NR \\
\hline Ball inside bowl & Put ball next to bowl & 6 & + & -- & NR \\
\hline Bowl next to plate & Put bowl on top of plate & 7 & + & -- & NR \\
\hline Fork inside cup & Put fork next to cup & 8 & + & -- & NR \\
\hline Cup next to plate & Put cup on top of plate & 9 & + & -- & NR \\
\hline & & Total & 19 & 19 & \\
\hline
\end{tabular}


Delayed Imitation of Actions with Objects (two sessions, 18 trials)

Materials: common objects (e.g., cup, utensils, ball), pencil, data sheet

$\underline{\text { Instructions for research assistant }}$

Present small bites of three preferred edibles to participant with statement "pick one". Provide the chosen edible for correct responses or after two consecutive incorrect responses.

Using the assigned object for the trial, say "do this" and complete one-step action with the object. Hold the object out of participant's view (e.g., under table) for 3s. Return the object to the table after $3 \mathrm{~s}$ and allow participant opportunity to complete action. Wait $5 \mathrm{~s}$ for the participant to respond, then remove object and set for next trial.

Scoring:

- +: if participant completes action independently within $5 \mathrm{~s}$, score +

- --: if the participant completes incorrect action within $5 \mathrm{~s}$, does not complete correct in $5 \mathrm{~s}$

- NR: if the participant does not respond within 5s

\begin{tabular}{|c|c|c|c|c|c|}
\hline & & Session 2 & & \\
\hline Starting position & Action & Date: & & \\
\hline Cup next to bowl & Put cup inside bowl & 1 & & & \\
\hline Fork inside cup & Put fork next to cup & 2 & + & -- & NR \\
\hline Ball inside bowl & Put ball next to bowl & 3 & + & -- & NR \\
\hline Bowl next to plate & Put bowl on top of plate & 4 & + & -- & NR \\
\hline Fork next to cup & Put fork in cup & 5 & + & -- & NR \\
\hline Ball next to plate & Put ball on top of plate & 6 & + & -- & NR \\
\hline Cup next to plate & Put cup on top of plate & 7 & + & -- & NR \\
\hline Ball next to cup & Put ball in cup & 8 & + & -- & NR \\
\hline Fork on top of plate & Put fork next to plate & 9 & + & -- & NR \\
\hline & & & & & \\
\hline
\end{tabular}


Delayed Picture-To-Object Match to Sample (two sessions, 18 trials total)

Materials: sample stimulus (i.e., picture), common objects (e.g., cup, utensils, ball), pencil, data sheet, stimulus board

\section{$\underline{\text { Instructions for research assistant (repeat for } 9 \text { trials) }}$}

Present small bites of three preferred edibles to participant with statement "pick one". Provide the chosen edible for correct responses or after two consecutive incorrect responses.

Using sample picture assigned to trial, present sample picture (in bold on data sheet) on the table. Wait $5 \mathrm{~s}$ for participant to point to sample picture. If participant does not point within $5 \mathrm{~s}$, prompt to point to sample with full physical prompt (i.e., hand-over-hand guidance).

After the participant points to the sample picture, remove sample picture for $3 \mathrm{~s}$ so it is out of participant's view (e.g., under table). After $3 \mathrm{~s}$, present stimulus board with three comparison stimuli in order shown on data sheet. Wait 5 s for the participant to respond, then remove comparison stimuli and set for next trial.

**Rotate comparison stimuli after each trial as shown on data sheet. That is, move stimulus in third position to first position and remaining stimuli down one position.

Scoring:

- +: if participant independently points to matching comparison stimulus within $5 \mathrm{~s}$

- --: if participant points to incorrect comparison stimulus within $5 \mathrm{~s}$

- NR: if participant does not respond within $5 \mathrm{~s}$

Date: $\underline{\text { Stimuli }}$

Session: 1

A: Cup

B: Fork

C: Ball

\begin{tabular}{|c|c|c|c|c|c|c|c|c|c|}
\hline Trial & 1 & 2 & 3 & 4 & 5 & 6 & 7 & 8 & 9 \\
\hline Stimuli & A B C & B C A & C A B & A B C & B C A & C A B & A B C & B C A & C A B \\
\hline & + & + & + & + & + & + & + & + & + \\
\hline & -- & -- & -- & -- & -- & -- & -- & -- & -- \\
\hline & NR & NR & NR & NR & NR & NR & NR & NR & NR \\
\hline $\begin{array}{c}\text { Total } \\
\text { correct }\end{array}$ & -19 & & & & & & & & \\
\hline
\end{tabular}


Delayed Picture-To-Object Match to Sample (two sessions, 18 trials total)

Materials: sample stimulus (i.e., picture), common objects (e.g., cup, utensils, ball), pencil, data sheet, stimulus board

\section{$\underline{\text { Instructions for research assistant (repeat for } 9 \text { trials) }}$}

Present small bites of three preferred edibles to participant with statement "pick one". Provide the chosen edible for correct responses or after two consecutive incorrect responses.

Using sample picture assigned to trial, present sample picture (in bold on data sheet) on the table. Wait $5 \mathrm{~s}$ for participant to point to sample picture. If participant does not point within $5 \mathrm{~s}$, prompt to point to sample with full physical prompt (i.e., hand-over-hand guidance).

After the participant points to the sample picture, remove sample picture for $3 \mathrm{~s}$ so it is out of participant's view (e.g., under table). After 3s, present stimulus board with three comparison stimuli in order shown on data sheet. Wait 5 s for the participant to respond, then remove comparison stimuli and set for next trial.

**Rotate comparison stimuli after each trial as shown on data sheet. That is, move stimulus in third position to first position and remaining stimuli down one position.

Scoring:

- +: if participant independently points to matching comparison stimulus within $5 \mathrm{~s}$

- --: if participant points to incorrect comparison stimulus within $5 \mathrm{~s}$

- NR: if participant does not respond within $5 \mathrm{~s}$

Date:

Session: 2 $\underline{\text { Stimuli }}$

A: Toothbrush

B: Book

C: Pen

\begin{tabular}{|c|c|c|c|c|c|c|c|c|c|}
\hline Trial & 1 & 2 & 3 & 4 & 5 & 6 & 7 & 8 & 9 \\
\hline Stimuli & A B C & B C A & C A B & A B C & B C A & C A B & A B C & B C A & C A B \\
\hline & + & + & + & + & + & + & + & + & + \\
\hline & -- & -- & -- & -- & -- & -- & -- & -- & -- \\
\hline & NR & NR & NR & NR & NR & NR & NR & NR & NR \\
\hline $\begin{array}{c}\text { Total } \\
\text { correct }\end{array}$ & $\mathbf{1 9}$ & & & & & & & & \\
\hline
\end{tabular}


Delayed Computer Picture-to-Object Match to Sample (two sessions, 18 trials total)

Materials: laptop, sample stimulus (i.e., picture on laptop), common objects (e.g., cup, utensils, ball), pencil, data sheet, stimulus board

\section{$\underline{\text { Instructions for research assistant (repeat for } 9 \text { trials) }}$}

Present small bites of three preferred edibles to participant with statement "pick one". Provided the chosen edible for correct responses or after two consecutive incorrect responses.

Using sample picture assigned to trial, present sample picture (in bold on data sheet) on laptop screen. Wait $5 \mathrm{~s}$ for participant to point to sample picture. If participant does not point within $5 \mathrm{~s}$, prompt to point to sample with full physical prompt (i.e., hand-over-hand guidance).

After the participant points to the sample picture, remove sample picture from the screen for $3 \mathrm{~s}$ (e.g., blank slide on screen). After $3 \mathrm{~s}$, present stimulus board with three comparison stimuli in order shown on data sheet. Wait $5 \mathrm{~s}$ for the participant to respond, then remove comparison stimuli and set for next trial.

**Rotate comparison stimuli after each trial as shown on data sheet. That is, move stimulus in third position to first position and remaining stimuli down one position.

Scoring:

- +: if participant independently points to matching comparison stimulus within $5 \mathrm{~s}$

- --: if participant points to incorrect comparison stimulus within $5 \mathrm{~s}$ (first stimulus only)

- NR: if participant does not respond within 5s

Date: $\underline{\text { Stimuli }}$

Session: 1

A: Cup

B: Fork

C: Ball

\begin{tabular}{|c|c|c|c|c|c|c|c|c|c|}
\hline Trial & 1 & 2 & 3 & 4 & 5 & 6 & 7 & 8 & 9 \\
\hline Stimuli & A B C & B C A & C A B & A B C & B C A & C A B & A B C & B C A & C A B \\
\hline & + & + & + & + & + & + & + & + & + \\
\hline & -- & -- & -- & -- & -- & -- & -- & -- & -- \\
\hline & NR & NR & NR & NR & NR & NR & NR & NR & NR \\
\hline $\begin{array}{c}\text { Total } \\
\text { correct }\end{array}$ & -19 & & & & & & & & \\
\hline
\end{tabular}


Delayed Computer Picture-to-Object Match to Sample (two sessions, 18 trials total)

Materials: laptop, sample stimulus (i.e., picture on laptop), common objects (e.g., cup, utensils, ball), pencil, data sheet, stimulus board

\section{$\underline{\text { Instructions for research assistant (repeat for } 9 \text { trials) }}$}

Present small bites of three preferred edibles to participant with statement "pick one". Provided the chosen edible for correct responses or after two consecutive incorrect responses.

Using sample picture assigned to trial, present sample picture (in bold on data sheet) on laptop screen. Wait $5 \mathrm{~s}$ for participant to point to sample picture. If participant does not point within $5 \mathrm{~s}$, prompt to point to sample with full physical prompt (i.e., hand-over-hand guidance).

After the participant points to the sample picture, remove sample picture from the screen for $3 \mathrm{~s}$ (e.g., blank slide on screen). After $3 \mathrm{~s}$, present stimulus board with three comparison stimuli in order shown on data sheet. Wait $5 \mathrm{~s}$ for the participant to respond, then remove comparison stimuli and set for next trial.

**Rotate comparison stimuli after each trial as shown on data sheet. That is, move stimulus in third position to first position and remaining stimuli down one position.

Scoring:

- +: if participant independently points to matching comparison stimulus within $5 \mathrm{~s}$

- --: if participant points to incorrect comparison stimulus within $5 \mathrm{~s}$ (first stimulus only)

- NR: if participant does not respond within $5 \mathrm{~s}$

Date:

Session: 2 $\underline{\text { Stimuli }}$

A: Toothbrush

B: Book

C: Pen

\begin{tabular}{|c|c|c|c|c|c|c|c|c|c|}
\hline Trial & 1 & 2 & 3 & 4 & 5 & 6 & 7 & 8 & 9 \\
\hline Stimuli & A B C & B C A & C A B & A B C & B C A & C A B & A B C & B C A & C A B \\
\hline & + & + & + & + & + & + & + & + & + \\
\hline & -- & -- & -- & -- & -- & -- & -- & -- & -- \\
\hline & NR & NR & NR & NR & NR & NR & NR & NR & NR \\
\hline $\begin{array}{c}\text { Total } \\
\text { correct }\end{array}$ & $\mathbf{1 9}$ & & & & & & & & \\
\hline
\end{tabular}




\section{Attending to a Video (1 session)}

Materials: laptop, 3 min preferred video, pencil, data sheet, interval timer

$\underline{\text { Instructions for research assistant }}$

Present 3 min preferred video (previously determined) on laptop and start interval timer.

Observe participant every 10 s for 2 s and record attending after each 2 s observation (i.e., 2 s observation, 8s recording).

Scoring:

- +: if participant's eyes (open) and head are oriented in the direction of laptop screen

- --: if participant's eyes closed, eyes and/or head oriented in direction other than laptop screen

\section{Date:}

\begin{tabular}{|c|c|c|c|c|c|c|c|c|c|c|c|c|c|c|c|c|c|c|}
\hline Interval & 1 & 2 & 3 & 4 & 5 & 6 & 7 & 8 & 9 & 10 & 11 & 12 & 13 & 14 & 15 & 16 & 17 & 18 \\
& + & + & + & + & + & + & + & + & + & + & + & + & + & + & + & + & + & + \\
& -- & -- & -- & -- & -- & -- & -- & -- & -- & -- & -- & -- & -- & -- & -- & -- & -- & -- \\
\hline $\begin{array}{c}\text { Total } \\
\text { attending }\end{array}$ & & & & & & & & & & & & & & & & & & \\
\hline
\end{tabular}


Appendix E: Social Validity Questionnaire

Participant:

Date:

After watching the video clips provided by the RA, please complete the following questions by placing a mark in the corresponding box.

\begin{tabular}{|l|l|l|c|c|c|}
\hline & $\begin{array}{c}1 \\
\text { Strongly } \\
\text { Disagree }\end{array}$ & $\begin{array}{c}2 \\
\text { Disagree }\end{array}$ & $\begin{array}{c}3 \\
\text { Neutral }\end{array}$ & $\begin{array}{c}4 \\
\text { Agree }\end{array}$ & $\begin{array}{c}5 \\
\text { Strongly } \\
\text { Agree }\end{array}$ \\
\hline Overall, I liked the procedures. & & & & & \\
\hline $\begin{array}{l}\text { The intervention increased consumption } \\
\text { of the target foods. }\end{array}$ & & & & & \\
\hline $\begin{array}{l}\text { I would continue to use this intervention } \\
\text { for other target foods. }\end{array}$ & & & & & \\
\hline $\begin{array}{l}\text { I would recommend this intervention to } \\
\text { others looking to treat food selectivity. }\end{array}$ & & & & & \\
\hline
\end{tabular}




\title{
Appendix F: IRB Letter of Approval
}

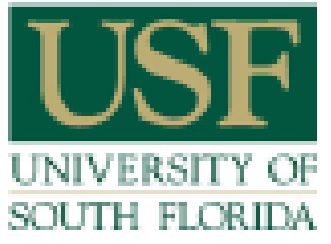

\author{
RESEARCH INTEGRITYAND COMPLLACE \\ Institutional Review Boands, FWA No. 00001669

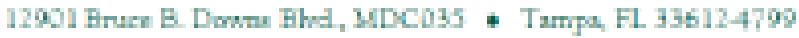

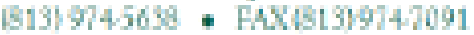

December 19,2016

Erin OConor

ABA-Applied Behavior Analysis

Tampa, FL 33612

\section{RE: Expedited Approwal for Initial Review}

IRE=. Pro00028257

Title: Treatment of Food Selectivity: An Evaluation of Video Modeling of Contingencies

Study Approval Period: 12/19/2016 to 12/19/2017

Dear Ms. OConnor:

On 12/9/2016, the Instintional Review Board (IRB) reviewed and APPROVED the above application and all documents contained within including those outlined below.

Approved Item(s):

Protocol Document(s):

PTotocol Versionl 11.23.16.docx

\section{Consent/Assent Document(s)":}

SB Assent Fonmpdif

SB Combined Consent and Parental Pennission pdf

SB LAR Version 1.docr.pdf

OConnor Thesis Verbal.Asgent Scrint docx

"Please use only the official IRB stamped informed consent/assent document(s) found under the "Aitaclments" tab. Please note, these consent/assent document(s) are only valid during the approval period indicated at the top of the form(s). (Child Verbal Assent is not a stamped form).

It was the detemination of the IRB that your study qualified for expedited review which includes activities that (1) present no more than mimimal risk to human subjects, and (2) imolve only procedures listed in ove or more of the categories outlined below. The IRB may review research through the expedited review procedure authorized by $45 \mathrm{CFR} 46.110$. The research 
proposed in this study is categorized uder the following expedited review category-

(6) Collection of data from voice, video, digital, or image recordings made for research purposes.

(7) Research on individual or group characteristics or behavior (including, but not limited to, research on perception, cognition, motivation, identity, language, commmmication, cultural beliefs or practices, and social behavior) or research enmloying survey, interview, oral history, focus group, program evaluation, human factors evaluation, or quality assurance methodologies.

Study involves children and falls umder 45 CFR 46.404: Research not imolving more than minimal risk.

As the principal investigator of this study, it is your responsibility to conchuct this study in accordance with $\mathbb{R B}$ policies and procechues and as approved by the IRB. Any changes to the approved research must be submitted to the IRB for review and approval via an amediment. Additionally, all unanticipated problems must be reported to the USF IRB within five (5) calendar days.

We appreciate your dedication to the ethical conduct of human subject research at the University of South Florida and your contimed conmiment to lmuman research protections. If you have any questions regarding this matter, please call 813-974-5638.
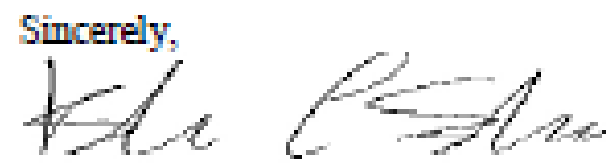

Kristen Salomon, PhD, Vice Chaiperson USF Institutional Review Board 